This document is the accepted manuscript version of the following article: L'Hôpital, E., Lothenbach, B., Scrivener, K., \& Kulik, D. A. (2016). Alkali uptake in calcium alumina silicate hydrate (C-A-S-H). Cement and Concrete Research, 85, 122-136. http://doi.org/10.1016/j.cemconres.2016.03.009

This accepted manuscript is made available under the CC-BY-NC-ND 4.0 license http://creativecommons.org/ licences/by-nc-nd/4.0/

\title{
1 Alkali uptake in calcium alumina silicate hydrate (C-A-S-H)
}

2 E. L'Hôpital ${ }^{1}$, B. Lothenbach ${ }^{1 *}$, K. Scrivener ${ }^{3}$, D.A. Kulik ${ }^{2}$

$3{ }^{1}$ Empa, Laboratory for Concrete \& Construction Chemistry, CH-8600 Dübendorf, Switzerland

$4 \quad{ }^{2}$ Paul Scherrer Institute, Laboratory for Waste Management, 5232 Villigen PSI, Switzerland

$5{ }^{3}$ EPFL, Laboratory of Construction Materials, CH-1015 Lausanne, Switzerland

6

7 Keywords: C-S-H, aluminium, alkali, characterization

8

9 Abstract: (max. 150 words)

10 Uptake of the alkalis $\mathrm{K}$ and $\mathrm{Na}$ by calcium silicate hydrate $(\mathrm{C}-\mathrm{S}-\mathrm{H}) \mathrm{gel}$ and calcium alumina silicate hydrate $(\mathrm{C}-\mathrm{A}-\mathrm{S}-\mathrm{H})$ of molar $\mathrm{Ca} / \mathrm{Si}$ ratios $=0.6$ to 1.6 and molar $\mathrm{Al} / \mathrm{Si}$ ratio $=0$ or 0.05 has been studied at $20^{\circ} \mathrm{C}$. Alkalis are thought to be bound in the interlayer space of C-A-S-H and show preferred uptake by lower $\mathrm{Ca} / \mathrm{Si}$ ratios and by higher alkali concentrations. A consequence of alkali uptake into $\mathrm{C}-\mathrm{A}-\mathrm{S}-\mathrm{H}$ is a rearrangement of the $\mathrm{C}-\mathrm{A}-\mathrm{S}-\mathrm{H}$ structure. Less calcium is present in the interlayer and shorter silica chains are observed.

No significant difference was observed between sodium and potassium uptake. Equilibration times of

1791 days to 1 year or the solid phase being either C-S-H or C-A-S-H had seemingly no effect on alkali uptake. 


\section{Introduction}

The alkalis potassium and sodium are common to all Portland cement (PC) based materials, but no solid phase buffers their concentration in the pore solution. A direct result of high alkali contents is therefore a high $\mathrm{pH}$ pore solution, which affects the dissolution of all other minerals in the PC system and therefore the concentrations of other elements [1-4]. In addition, alkali and hydroxide concentrations in the pore solution determine whether and to what extent alkali silica reaction (ASR) can occur in concrete $[5,6]$. The risk of ASR can be lowered by the addition of supplementary cementitious materials such as fly ash or silica fume, which act to decrease the $\mathrm{Ca} / \mathrm{Si}$ ratio of $\mathrm{C}-\mathrm{S}-\mathrm{H}$, leading to higher alkali uptake in its structure. Alkalis in PC based materials are mainly taken up by C$\mathrm{S}-\mathrm{H}$, with only negligible amounts being taken up by other mineral hydrates such as portlandite, ettringite, hydrogarnet, or hydrotalcite [7, 8]. Rather than being phase pure however, C-S-H in PC based materials is a C-A-S-H gel, which becomes increasingly significant if a high aluminium content supplementary cementitious material is added $[9,10]$. A detailed knowledge of the alkali uptake in CA-S-H gel is therefore important.

Experiments with synthetic C-S-H $[3,11]$ and low pH cements $[1,12,13]$ indicate that more alkalis are taken up into low-Ca/Si C-S-H than into high-Ca/Si C-S-H. A strong correlation between dissolved alkali concentrations and alkali uptake by C-S-H in the concentration range up to $300 \mathrm{mmol} / \mathrm{L}[1,3,14]$ was observed. At higher alkali concentrations of $500-1500 \mathrm{mmol} / \mathrm{L}$, the alkali uptake by $\mathrm{C}-\mathrm{S}-\mathrm{H}$ increases less strongly with concentration, and maximum molar ratios of $\mathrm{Na} / \mathrm{Si}$ and $\mathrm{K} / \mathrm{Si}=0.3-0.5$ in $\mathrm{C}$ S-H have been reported [11, 14].

Alkali sorption studies have identified either preferred or equivalent sodium or potassium sorption $[1,3$, 11, 15-18]. Preferred sodium sorption was used to interpret pore solution analysis of PC by Taylor [19] and has also been measured for synthetic C-S-H gel [15]. Preferred potassium sorption, however, has also been measured on synthetic $\mathrm{C}-\mathrm{S}-\mathrm{H}$ [1]. Sodium as $\mathrm{Na}^{+}$has a larger solvated ionic radius than $\mathrm{K}^{+}$ and so sodium uptake might be physically inhibited, which is consistent with observations of [1], but contradicts preferential sodium sorption $[11,15,19]$.

Hong and Glasser [20] reported a strong increase of alkali sorption in the presence of C-A-S-H gel as opposed to $\mathrm{C}-\mathrm{S}-\mathrm{H}$ gel alone, and suggested that the replacement of $\mathrm{SiO}_{2}$ by $\mathrm{AlO}_{2}^{-}$would further increase alkali uptake to maintain charge balance. In contrast, Stade [11] observed less alkali uptake in 
C-A-S-H than in C-S-H, while Chappex and Scrivener [8] and Bach et al. [1] observed no significant difference in the alkali uptake whether aluminium was present or not. It also has been suggested that alkalis may charge-balance the silanol group by the substitution of protons $\left(\mathrm{SiOH}+\mathrm{K}^{+}+\mathrm{OH}_{-}^{-} \rightarrow \mathrm{SiO}^{-}\right.$ $\left.\ldots \mathrm{K}^{+}+\mathrm{H}_{2} \mathrm{O}\right)$ or of calcium ions $\left(\mathrm{SiOH}+\mathrm{Ca}^{2+}+\mathrm{OH}-\rightarrow \mathrm{SiOCa}^{+}+\mathrm{H}_{2} \mathrm{O} / \mathrm{SiOCa}^{+}+\mathrm{K}^{+} \rightarrow \mathrm{SiO}^{-} \ldots \mathrm{K}^{+}+\right.$ $\left.\mathrm{Ca}^{2+}\right)[3,11,21]$, or occupy empty sites in the interlayer [21].

The scatter of results reported in the literature indicates either that a large experimental error is associated with the measurement of alkali uptake, that the synthesis protocol has an important influence, and/or that a number of different mechanisms are responsible for the alkali uptake in C-S-H and $\mathrm{C}-\mathrm{A}-\mathrm{S}-\mathrm{H}$, such that the results may vary depending on the alkali concentration, the C-S-H composition, and the presence of other ions or solids. Moreover, ${ }^{23} \mathrm{Na}$ NMR data indicate the presence of two different sites for sodium binding in C-S-H $[22,23]$.

In order to elucidate these seeming contradictions, the focus of the present paper was on the uptake of the alkalis by synthetic C-A-S-H gel. Solid phases were characterized by thermal gravimetric analysis (TGA), X-ray diffraction (XRD) and ${ }^{29} \mathrm{Si}$ nuclear magnetic resonance (NMR) and the liquid phase by $\mathrm{pH}$ measurement and composition by ionic chromatography (IC). 


\section{Materials and methods}

Both C-S-H and C-A-S-H gels were synthesized by a one-step protocol at $20^{\circ} \mathrm{C}$ as described in detail previously $[4,24]$ and summarized below.

\subsection{Synthesis}

Calcium oxide $(\mathrm{CaO})$, silica fume $\left(\mathrm{SiO}_{2}\right)$ and monocalcium aluminate $\left(\mathrm{CA}: \mathrm{CaO} \cdot \mathrm{Al}_{2} \mathrm{O}_{3}\right)$ were used in different proportions to synthesize $\mathrm{C}-\mathrm{A}-\mathrm{S}-\mathrm{H}$. $\mathrm{Ca} / \mathrm{Si}$ ratios $=0.6,0.8,1.0,1.2,1.4$ and 1.6 and $\mathrm{Al} / \mathrm{Si}=$ 0.05 were targeted as detailed in Appendix A. For comparison, the alkali uptake on some C-S-H samples without aluminium was also studied. In addition, samples with $\mathrm{Ca} / \mathrm{Si}=1.0$ and $\mathrm{Al} / \mathrm{Si}=0.1$ were synthetized and studied by ${ }^{29} \mathrm{Si}$ NMR as described previously [4]. Water to solid mass ratio equal to 45 was used to ensure the homogeneity of the samples. C-S-H and C-A-S-H was equilibrated in Milli-Q water or in potassium or sodium hydroxide solutions with a concentration between 0.01 and 0.5 mol/L. Synthesis and all sample handling were made in a $\mathrm{N}_{2}$-filled glove box to minimize $\mathrm{CO}_{2}$ contamination. For each equilibration time, a separate sample was prepared, which was stored in a $100 \mathrm{~mL}$ PE-HD container placed on a horizontal shaker moving at $100 \mathrm{rpm}$, and equilibrated at $20^{\circ} \mathrm{C}$. After different equilibration times, the solid and liquid phase were separated by filtration using $0.45 \mu \mathrm{m}$ nylon filters and subsequently analysed.

\subsection{Solid phase analysis}

After filtration, the solid was washed with $30 \mathrm{~mL}$ of a $50 \%-50 \%$ water-ethanol solution, afterwards with $30 \mathrm{~mL}$ pure ethanol, dried for seven days by freeze drying, and then stored until analysis in $\mathrm{N}_{2}$-filled desiccators in the presence of saturated $\mathrm{CaCl}_{2}$ solutions $(\approx 30 \% \mathrm{RH})$ and of $\mathrm{NaOH}$ pellets to act as a $\mathrm{CO}_{2}$ trap. The solid phases were analysed by TGA, XRD/pattern decomposition and ${ }^{29} \mathrm{Si} \mathrm{NMR.}$

TGA data were measured with a TGA/SDTA $851^{\mathrm{e}}$ Mettler Toledo device using approximately $30 \mathrm{mg}$ of sample. The weight loss of the samples was recorded from $30^{\circ} \mathrm{C}$ up to $980^{\circ} \mathrm{C}$ with a heating rate of $20^{\circ} \mathrm{C} /$ min under $\mathrm{N}_{2}$ atmosphere. The amount of portlandite was quantified from the weight loss around $450^{\circ} \mathrm{C}$ using the tangential method and the total water bound in the sample from the total water loss between 30 and $550^{\circ} \mathrm{C}$. The water bound in C-S-H and C-A-S-H was the difference between the total water loss and the weight loss due to portlandite. 
X-ray powder diffraction patterns were recorded on a PANalycatical X'Pert Pro MDF diffractometer equipped with a X'Celerator detector. Diffraction patterns were collected in increments of $5^{\circ}$ from $70^{\circ}$ $2 \theta$ at a conventional step size of $0.017^{\circ} 2 \theta$ and a step measurement time of 460 s.

Phase composition was determined with X'Pert HighScore Plus. Pattern decompositions were carried out with calcium fluoride as external standard. This method avoids the normalization to $100 \mathrm{wt} \%$; quantification of X-ray amorphous solids such as C-S-H can be determined by indirect measurement [4]. To determine the exact peak shifts position, anatase was added to some samples as internal standard.

The ${ }^{29} \mathrm{Si}$ NMR measurements were performed at room temperature using a Bruker Avance $400 \mathrm{MHz}$ NMR spectrometer with a $7 \mathrm{~mm}$ CP/MAS probe. The ${ }^{29} \mathrm{Si}$ MAS NMR single pulse experiments were recorded at $79.49 \mathrm{MHz}$ using the following parameters: $4500 \mathrm{~Hz}$ spinning speed, 9216 scans, $\frac{\pi}{3}$ pulses of $2.5 \mu \mathrm{s}, 20 \mathrm{~s}$ relaxation delays, the $90^{\circ}$ Pulse at the decoupling power level of $8 \mathrm{~dB}$ is $7.5 \mu \mathrm{s}$. The RF field is calculated by $1 /\left(4^{*} 7.5 \mu \mathrm{s}\right)=33.3 \mathrm{kHz}$. The chemical shifts of the ${ }^{29} \mathrm{Si}$ MAS NMR spectra were referenced to an external sample of tetramethylsilane (TMS). The observed ${ }^{29} \mathrm{Si}$ resonances were analysed using the $\mathrm{Q}^{\mathrm{n}}(\mathrm{mAl})$ classification, where a Si tetrahedron is connected to $\mathrm{n}$ Si tetrahedral with $\mathrm{n}$ varying from 0 to 4 and $\mathrm{m}$ is the number of neighbouring $\mathrm{AlO}_{4}$ tetrahedra.

Deconvolution of the Si-NMR data was carried out using the dmfit software [25]. Peak shapes were constrained as pseudo-voigt using a Lorentzian/Gaussian ratio $=0.5$, full width at half height $\leq 3 \mathrm{ppm}$ and constant chemical shifts between the different peaks as described in [4]. The dreierketten structure of the C-S-H was respected by defining the ratio $Q_{p}^{2} /\left(Q_{b}^{2}+Q^{2}{ }_{u}\right)$ equal to 2 , as for each bridging tetrahedra two pairing tetrahedra are present, as shown in Fig. $1 . Q^{2}{ }_{b}$ denotes the number of bridging tetrahedra neighbouring $\mathrm{Ca}$ in the interlayer, $\mathrm{Q}_{\mathrm{b}}^{2} \mathrm{OH}$ stand for bridging tetrahedra neighbouring $\mathrm{H}^{+}$in the interlayer, $\mathrm{Q}_{\mathrm{p}}^{2}$ are the pairing tetrahedra. The mean dreierketten chain length $(\mathrm{MCL})$ was calculated using equation 1 , and the $\mathrm{Al} / \mathrm{Si}$ ratio with equation 2 .

$$
M C L=\frac{2\left(Q^{1}+Q_{p}^{2}+Q_{b}^{2}+Q_{u}^{2}+\frac{3}{2} Q^{2}(1 A l)\right)}{Q^{1}}
$$

$$
\frac{A l}{S i}=\frac{\frac{1}{2} Q^{2}(1 A l)}{Q^{1}+Q_{p}^{2}+Q_{b}^{2}+Q_{u}^{2}+Q^{2}(1 A l)}
$$




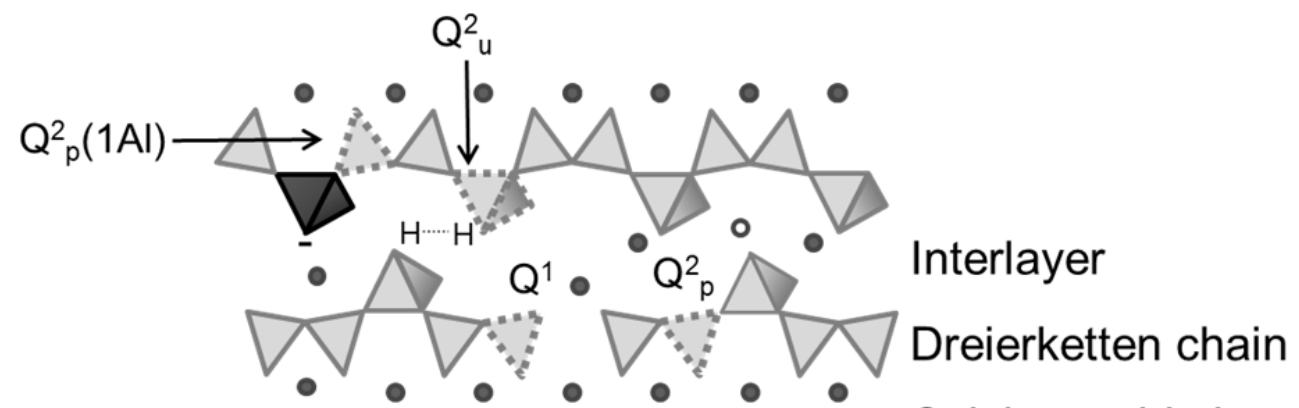

Calcium oxide layer

Figure 1: Schematic structure of C-A-S-H. Grey circle: calcium ion; empty circle: ion in the interlayer (water or alkali); light grey tetrahedra: protonated silicate; dark grey tetrahedra: aluminium; -: negative charge (compensated by proton, calcium or other cations). $Q_{(\mathrm{mAl})}^{\mathrm{n}}$ : $\mathrm{n}$ indicates the numbers of $\mathrm{Si}$ neighbours and $\mathrm{m}$ the number of aluminium neighbours, b: bridging position, $\mathrm{p}$ : pairing position. [4]
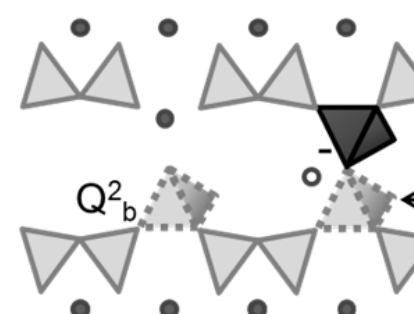

Dreierketten chain Interlayer

\subsection{Solution analysis}

The elemental concentrations of calcium, silicon, sodium, potassium and aluminium in the filtrates were determined with a Dionex DP ICS-3000 ion chromatograph. Each sample was diluted by a factor of $1,5,10,100$, and/or 1000 so that the standard solutions used of $0.1,0.5,1.0,5.0,10.0,25.0$ and $50.0 \mathrm{mg} / \mathrm{L}$ correctly bracketed all concentrations up to $50,000 \mathrm{mg} / \mathrm{L}$. Samples were measured in duplicate. The relative error of the measurements was $\leq 10 \%$ of the measured value. Silicon was analysed using sodium carbonate/bicarbonate eluent and sodium molybdate, and sodium lauryl sulfate in metasulfonic acid as a post-column reagent using an ion pack AS22 column.

To quantify the hydroxide concentration, $\mathrm{pH}$ measurements were performed at room temperature with a Knick pH meter (pH-Meter 766) equipped with a Knick SE100 electrode. The pH electrode was calibrated against $\mathrm{KOH}$ solutions of known concentrations in order to minimize the alkali error. The measurements were corrected to correspond to $20^{\circ} \mathrm{C}$.

The amount of alkalis bound in the solid was determined by an indirect and a direct method. The indirect method used a mass balance calculation from the alkali concentration in solution. The relative error of the measured dissolved alkali concentrations is around $5-10 \%$, which can lead to a large (up 
to $100 \%$ ) analytical error in the quantity of bound alkalis calculated from the mass balance approach, especially at high alkali concentrations. In the presence of $500 \mathrm{mmol} / \mathrm{L}$ potassium hydroxide, the relative error is $50 \mathrm{mmol} / \mathrm{L}$, which represents in terms of a $\mathrm{K} / \mathrm{Si}$ ratio an error of 0.3 (calculation based on the $\mathrm{Ca} / \mathrm{Si}=1.0)$. Thus, in addition, a direct method was used where the amount of alkali bound in the solid was determined by dissolving $20 \mathrm{mg}$ of the solid sample in $10 \mathrm{~mL}$ of $0.1 \mathrm{~mol} / \mathrm{L} \mathrm{HCl}$; the amount of bound alkalis was then quantified by ionic chromatography. For both methods, the error was calculated with a $95 \%$ confidence interval. For the indirect method, three independent measurements at three different times were carried out as shown in section 3.3.4 and for the direct method, each dissolution was repeated three times.

\subsection{Thermodynamic modelling}

GEMS-Selektor v3.0 (http://gems.web.psi.ch [26, 27]) is a chemical thermodynamic modelling code capable of calculating equilibrium between solid, liquid and gas phases. Solid solutions can be included and saturation indices of solids [28] can be calculated. The built-in GEMS thermodynamic database $[29,30]$ was used, enhanced with thermodynamic data for cement minerals taken from the cemdata07 database $[31,32]$ updated with the recent solubility products of calcium aluminate hydrates and hydrogarnet [33, 34] and for C-S-H, using the CSHQ model by Kulik [35].

The activity of each species was calculated from the measured total concentrations at $20^{\circ} \mathrm{C}$ using GEM-Selektor. The activity coefficients of the aqueous species $\gamma_{i}$ were computed with the built-in extended Debye-Hückel equation with common ion-size parameter $a_{i}$ of $3.67 \AA$ for $\mathrm{KOH}$ and of $3.31 \AA$ for $\mathrm{NaOH}$ solutions [36]:

$$
\log _{10} \gamma_{i}=\frac{-A_{\gamma} z_{i}^{2} \sqrt{I}}{1+B_{\gamma} a_{i} \sqrt{I}}+b_{\gamma} I
$$

where $z_{i}(-)$ denotes the charge of species $I, I\left(\mathrm{~mol} \mathrm{~kg}^{-1}\right)$ the effective molal ionic strength, $b_{y}(-)$ is a semi-empirical parameter $\left(0.123\right.$ for $\mathrm{KOH}$ and 0.098 for $\mathrm{NaOH}$ at $\left.25^{\circ} \mathrm{C}[36]\right)$, and $A_{\gamma}$ and $B_{\gamma}$ are $P, T$ dependent coefficients; at $20^{\circ} \mathrm{C}$ and 1 bar, $A_{\gamma} \approx 0.507 \mathrm{~kg}^{0.5} \cdot \mathrm{mol}^{-0.5}$ and $B_{\gamma} \approx 0.328 \mathrm{~kg}^{0.5} \cdot \mathrm{mol}^{-0.5} . \AA^{-1}$. The activity of water was calculated from the osmotic coefficient, $\varphi$, and the sum of all species molalities, $m_{z}$, according to Helgeson et al [36] (Ina $\left.a_{\text {water }}=-\varphi m_{z} / 55.508\right)$. This activity correction is thought to be applicable up to approx. $1 \mathrm{M}$ ionic strength [37]. 


\section{Results and discussion}

\subsection{Effect of alkali on the solids}

171

The presence of alkalis in C-A-S-H had little influence on the solids formed. In all cases, C-A-S-H is the main solid precipitated, as shown by the TGA and XRD data in Figure 2 to Figure 5 for C-A-S-H samples with $0.05 \mathrm{Al} / \mathrm{Si}$ ratio. A small quantity of portlandite is observed for higher concentrations of alkali hydroxide (Figure 2) and/or for high $\mathrm{Ca} / \mathrm{Si}$ ratios (Figure 3). At high $\mathrm{NaOH}$ and $\mathrm{KOH}$ concentrations, the TGA data indicate an additional weight loss at $400^{\circ} \mathrm{C}$, which is not associated with any crystalline phase in the XRD and was thus tentatively assigned to a calcium potassium sodium aluminate silicate hydrate (C-K-N-A-S-H) gel. The same weight loss at around $400^{\circ} \mathrm{C}$ is observed for samples prepared at $50{ }^{\circ} \mathrm{C}[38]$.

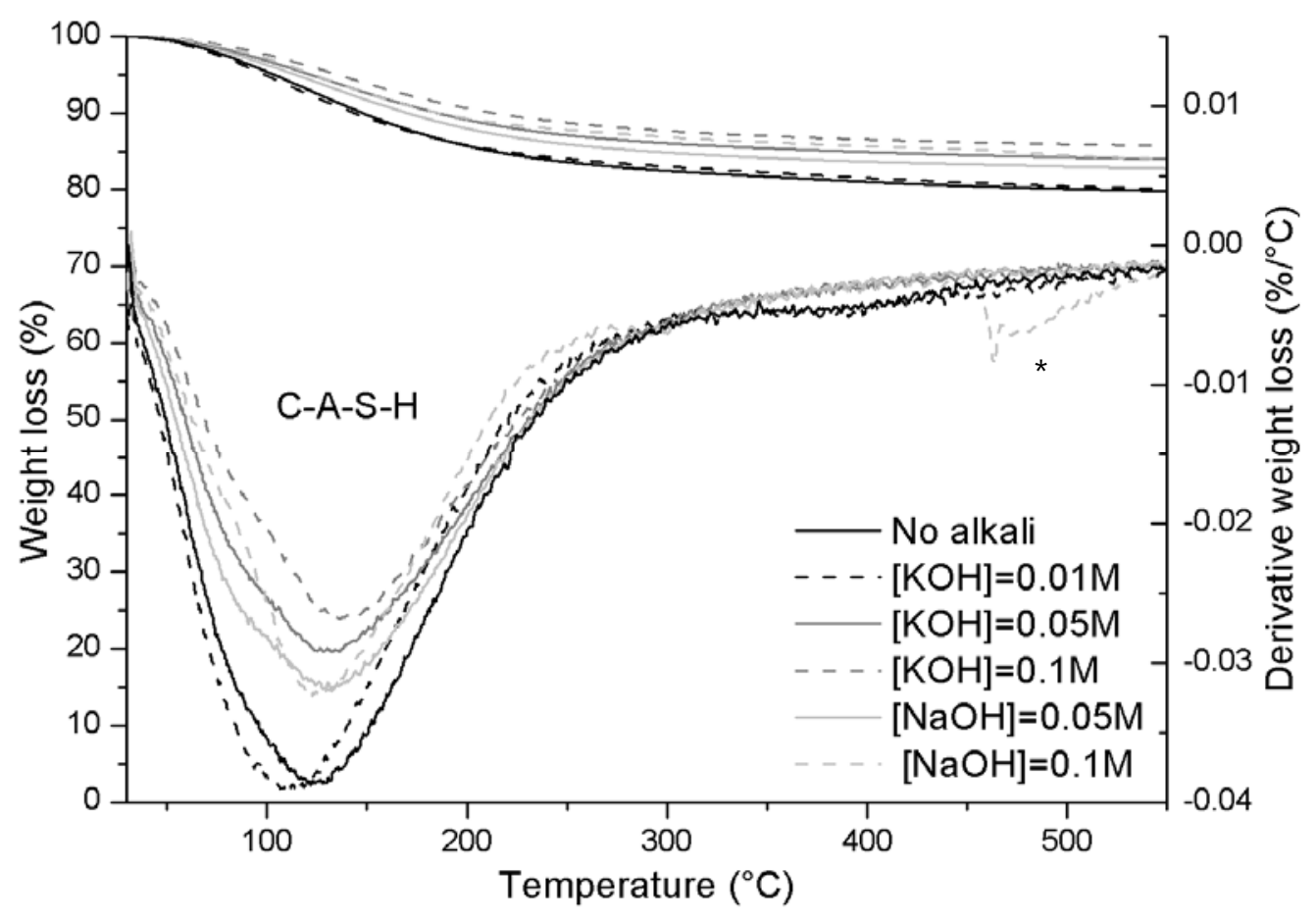

Figure 2: TGA of $\mathrm{C}-\mathrm{A}-\mathrm{S}-\mathrm{H}$ with target $\mathrm{Ca} / \mathrm{Si}=0.8$ and $\mathrm{Al} / \mathrm{Si}=0.05$ after an equilibration time of 182 days at different alkali concentrations. ${ }^{*}$ The weight loss between 450 to $500^{\circ} \mathrm{C}$ in $0.1 \mathrm{M} \mathrm{NaOH}$ is tentatively assigned to the decomposition of C-K-N-A-S-H. This weight loss has been observed for $\mathrm{Ca} / \mathrm{Si}=0.6$ and $\mathrm{Ca} / \mathrm{Si}=0.8$ with $0.1 \mathrm{M} \mathrm{NaOH}$. Similar weight loss have also been observed at $50{ }^{\circ} \mathrm{C}$ [38]. 


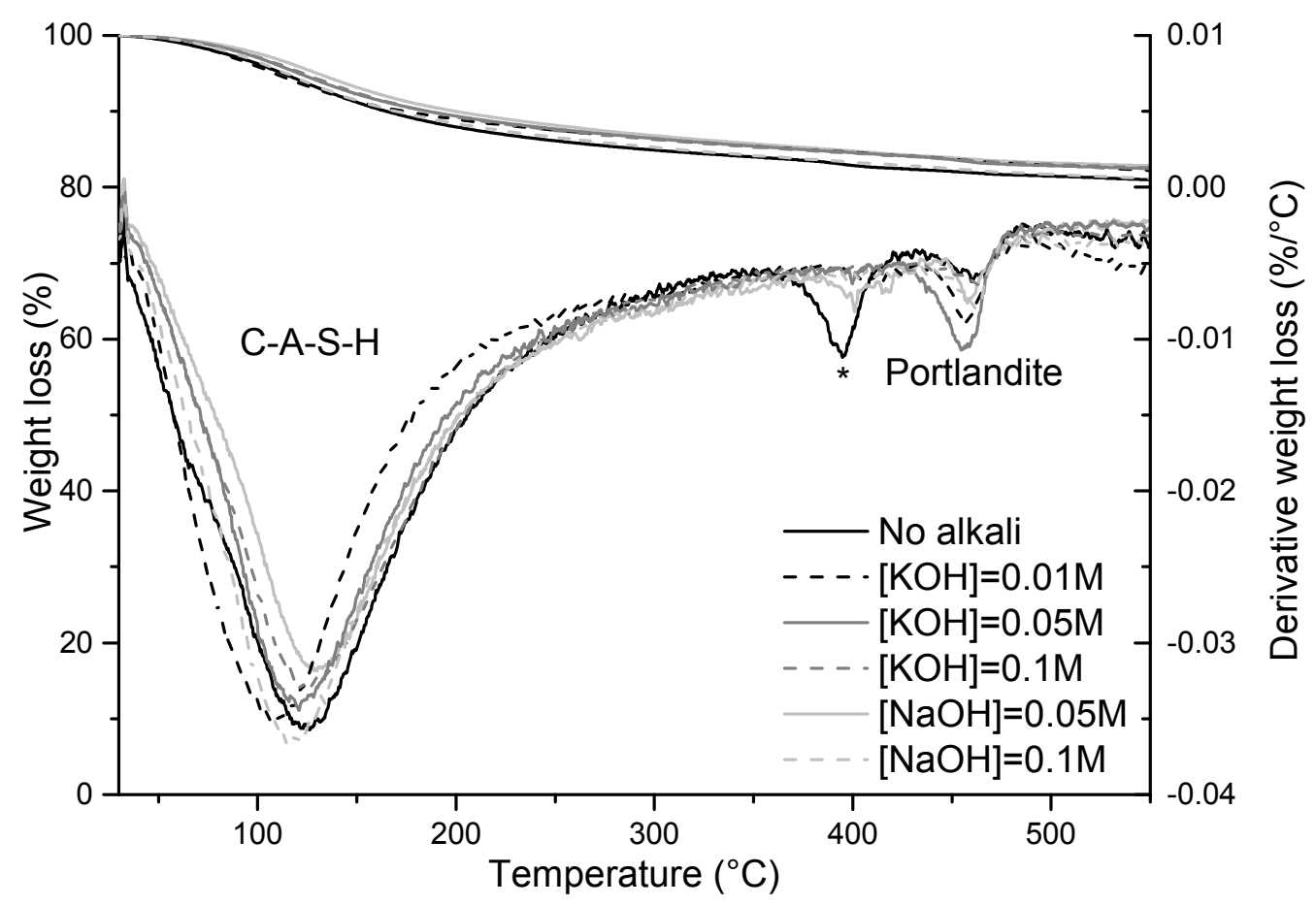

187

Figure 3: TGA of $\mathrm{C}-\mathrm{A}-\mathrm{S}-\mathrm{H}$ with target $\mathrm{Ca} / \mathrm{Si}=1.6$ and $\mathrm{Al} / \mathrm{Si}=0.05$ after an equilibration time of 182 days at different alkali concentration. In some samples, an additional weight loss at $400^{\circ} \mathrm{C}$ was observed $\left({ }^{*}\right)$, indicating the presence of very finely dispersed and somewhat coarser portlandite.

XRD indicates that the presence of alkali hydroxide decreases the mean basal spacing of the C-A-S-H as shown in Figure 4 for $\mathrm{Ca} / \mathrm{Si}=0.8$, and in Figure 5 for $\mathrm{Ca} / \mathrm{Si}=1.2$. An increase of the alkali concentration from 0 to $0.1 \mathrm{~mol} / \mathrm{L}$ leads to a decrease of the mean basal spacing from 12.7 to $\approx 12.1 \AA$ for $\mathrm{Ca} / \mathrm{Si}=1.2$ and to $\approx 13.3 \AA$ at $\mathrm{Ca} / \mathrm{Si}=0.8$, as shown in Figure 6 . No well-defined $\mathrm{d}_{002}$ diffraction peak is observed in our samples for $\mathrm{Ca} / \mathrm{Si} \leq 0.8$, but other studies report a $\mathrm{d}_{002}$ peak at $\approx 14 \AA$ for $\mathrm{Ca} / \mathrm{Si}=0.8$ [39], consistent with the $d_{002}$ of $14 \AA$ tobermorite [40]. At Ca/Si ratios $>1.2$, where only a small amount of alkali uptake occurs, no significant influence of alkali hydroxide is found. Similarly to the observations reported here, a decrease of the mean basal spacing in the presence of sodium hydroxide has been observed by Lognot [41] and by Bach et al. [1].

Changes in the local bonding environment caused by a partial replacement of protons and calcium ions with potassium and sodium ions in the interlayer is a likely key factor contributing to the reduction in basal spacing, although at present the precise mechanism is unclear. 
At equal concentrations, potassium and sodium have a similar effect of reducing the mean basal spacing. This is in contrast to the observations of Bach et al. [1], who observed a stronger decrease of the mean basal spacing in the presence of sodium hydroxide than of potassium hydroxide. The reasons for these contradictory observations are unclear, although they might be related to different washing procedures of the solids, the less harsh drying, and the shorter equilibration times used in the study of Bach et al. [1].

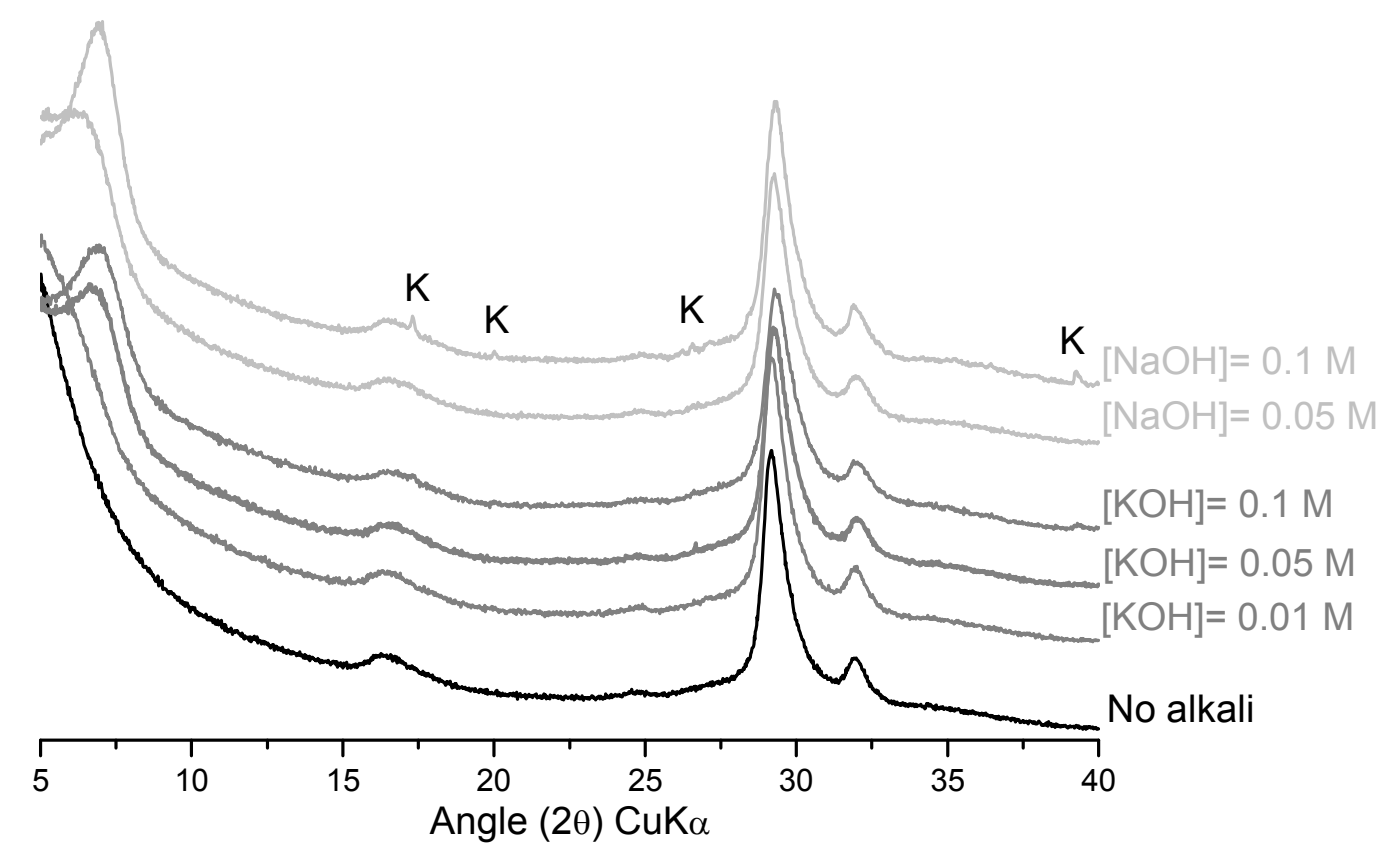

Figure 4: XRD diffractograms of $\mathrm{C}-\mathrm{A}-\mathrm{S}-\mathrm{H}$ with $\mathrm{Ca} / \mathrm{Si}=0.8$ and $\mathrm{Al} / \mathrm{Si}=0.05$ in different alkali solutions after an equilibration time of 182 days. K: katoite. 


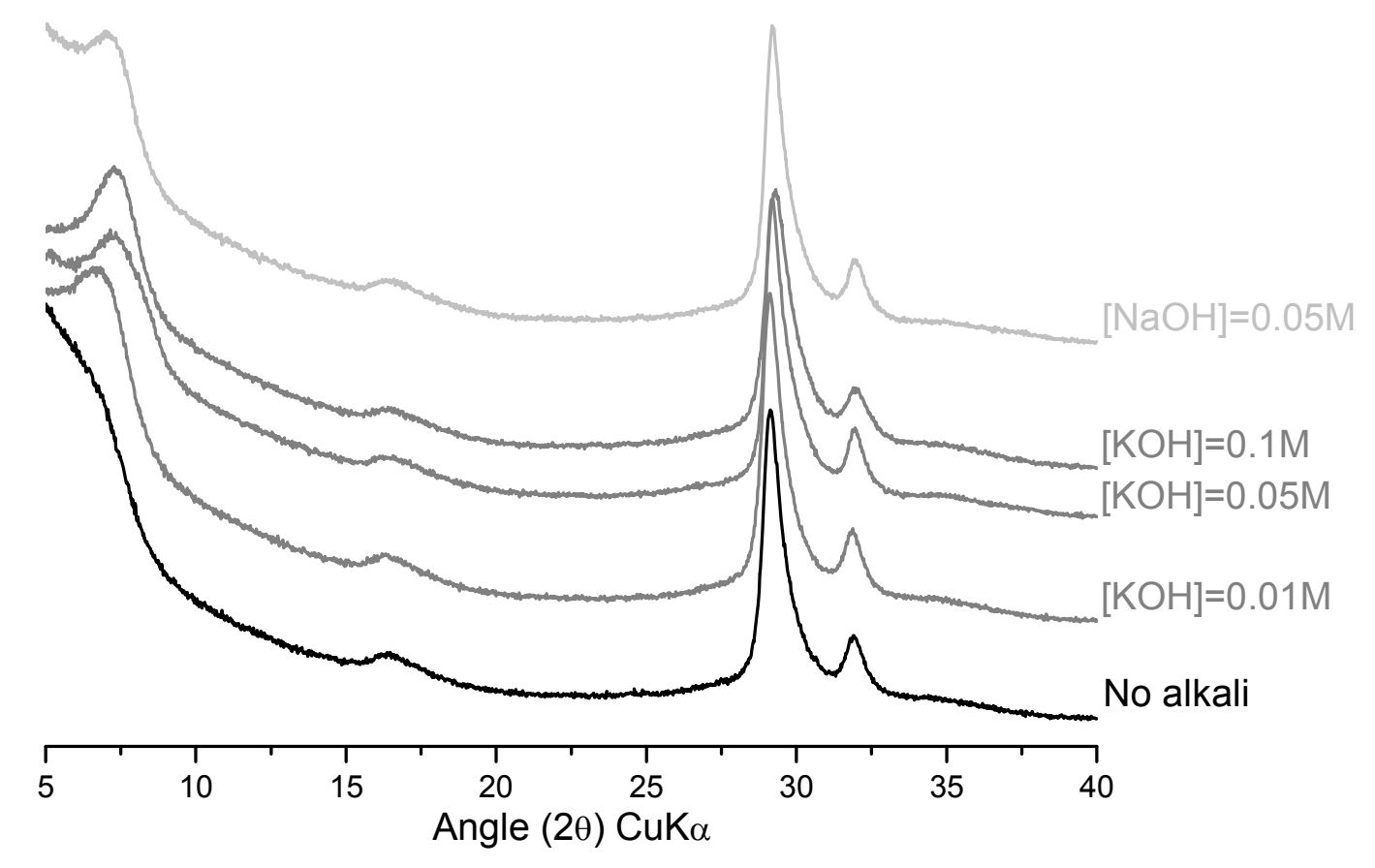

Figure 5: XRD diffractograms of $\mathrm{C}-\mathrm{A}-\mathrm{S}-\mathrm{H}$ with $\mathrm{Ca} / \mathrm{Si}=1.2$ and $\mathrm{Al} / \mathrm{Si}=0.05$ in different alkali solutions after an equilibration time of 182 days.

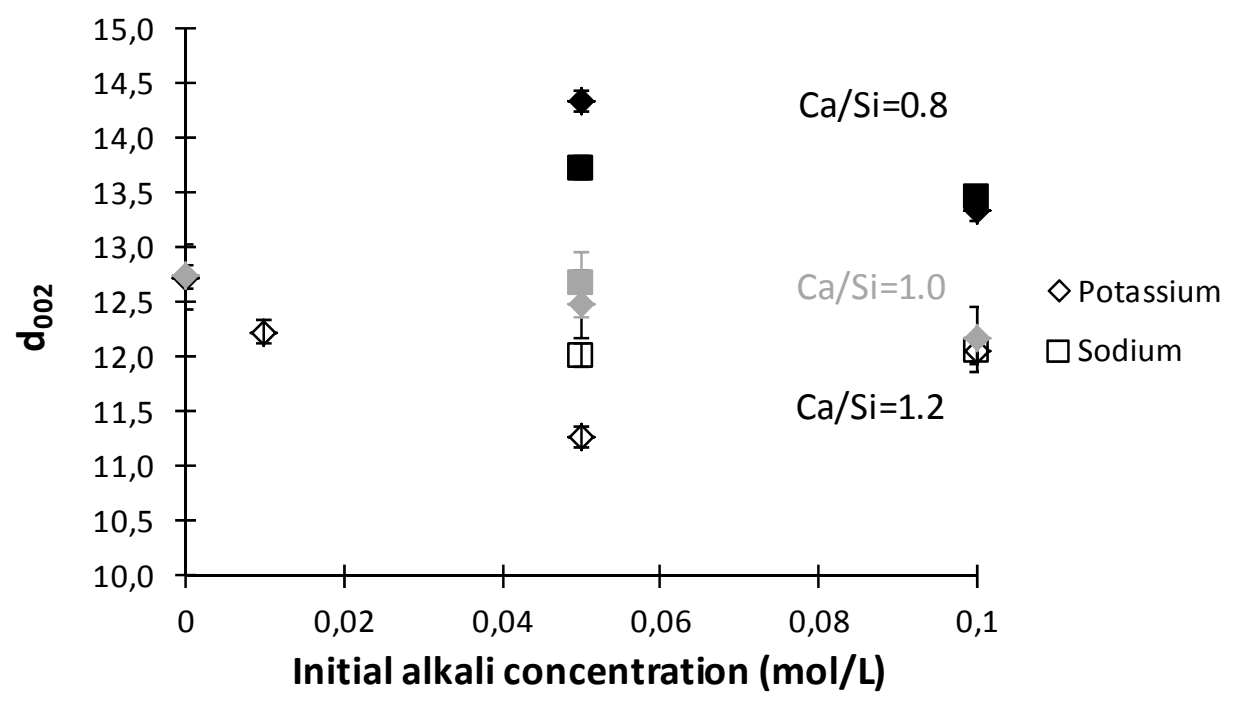

Figure 6: Mean basal spacing of $\mathrm{C}-\mathrm{A}-\mathrm{S}-\mathrm{H}(\mathrm{Al} / \mathrm{Si}=0.05)$ as a function of initial alkali concentration after an equilibration time of 1 year (measured with anatase as an internal standard). Empty symbol: $\mathrm{Ca} / \mathrm{Si}=1.2$, grey symbol: $\mathrm{Ca} / \mathrm{Si}=1.0$, dark symbol: $\mathrm{Ca} / \mathrm{Si}=0.8$, diamond: $\mathrm{C}-\mathrm{A}-\mathrm{S}-\mathrm{H}$ with a solution of potassium hydroxide, square: C-A-S-H with a solution of sodium hydroxide. 
Four main different environments of silica in C-A-S-H can be observed by ${ }^{29}$ Si-NMR as illustrated in Figure 7. The end of chain silica $\left(Q^{1}\right)$ has a chemical shift in the range of -79.1 to $-79.6 \mathrm{ppm}$, the bridging silica $\left(Q_{b}^{2}\right)$ from -83.3 to -83.4 ppm, the pairing silica $\left(Q_{p}^{2}\right)$ from -84.7 to -85.3ppm [4, 42, 43], and the bridging tetrahedra connected by hydrogen bonding $\left(Q^{2}{ }_{u}\right)$ at $\sim-88.3 \mathrm{ppm}[4,44-46]$. The presence of aluminium introduces an additional peak at -81.5 ppm, $\mathrm{Q}_{\mathrm{p}}^{2}(1 \mathrm{Al})[47-51]$.

As previously observed for C-A-S-H samples equilibrated at $20{ }^{\circ} \mathrm{C}[4,52]$ and at $50{ }^{\circ} \mathrm{C}$ [38], the presence of alkali increases the relative $Q^{1}$ intensity, indicating a decrease of the dreierketten chain length, as shown in Table 1 and Figure 7 . The potassium or sodium uptake results in a $1-3$ ppm chemical shift to less negative values. In agreement with our data, a decrease of the silica chain length $[22,52,53]$ and of the chemical shift $[4,21,22]$ has been observed by different authors. Typically, the shielding of silica sites by protons or alkalis is weaker than by calcium, leading to less negative chemical shifts [54-56]. The less negative chemical shifts in the presence of alkali hydroxides indicate a decrease of the fraction of silica bound to calcium and a binding of silica to sodium or potassium ions. High alkali concentrations result in the replacement of a part of the divalent calcium ions at the surface by monovalent ions (potassium or sodium) as visible by the lower zeta potential of the C-S-H $[4,57,58]$. The replacement of calcium at the surface and in the interlayer by alkali ions leads to a structural reorganization of $\mathrm{C}-\mathrm{S}-\mathrm{H}$ and $\mathrm{C}-\mathrm{A}-\mathrm{S}-\mathrm{H}$ as the total $\mathrm{Ca} / \mathrm{Si}$ ratio in the experiment is constant. The calcium removed from the interlayer is integrated in the main $\mathrm{CaO}$ plane of C-A-S-H as also illustrated in Figure 7B. The increase of the fraction of $\mathrm{CaO}$ main layer leads to a rearrangement in the silica chains, i.e. to the presence of more silica dimers consistent with the shorter silica chain observed in presence of alkali with the increase of the relative $Q^{1}$ intensities, as shown in Table 1 and Figure $7 \mathrm{~A}$. 


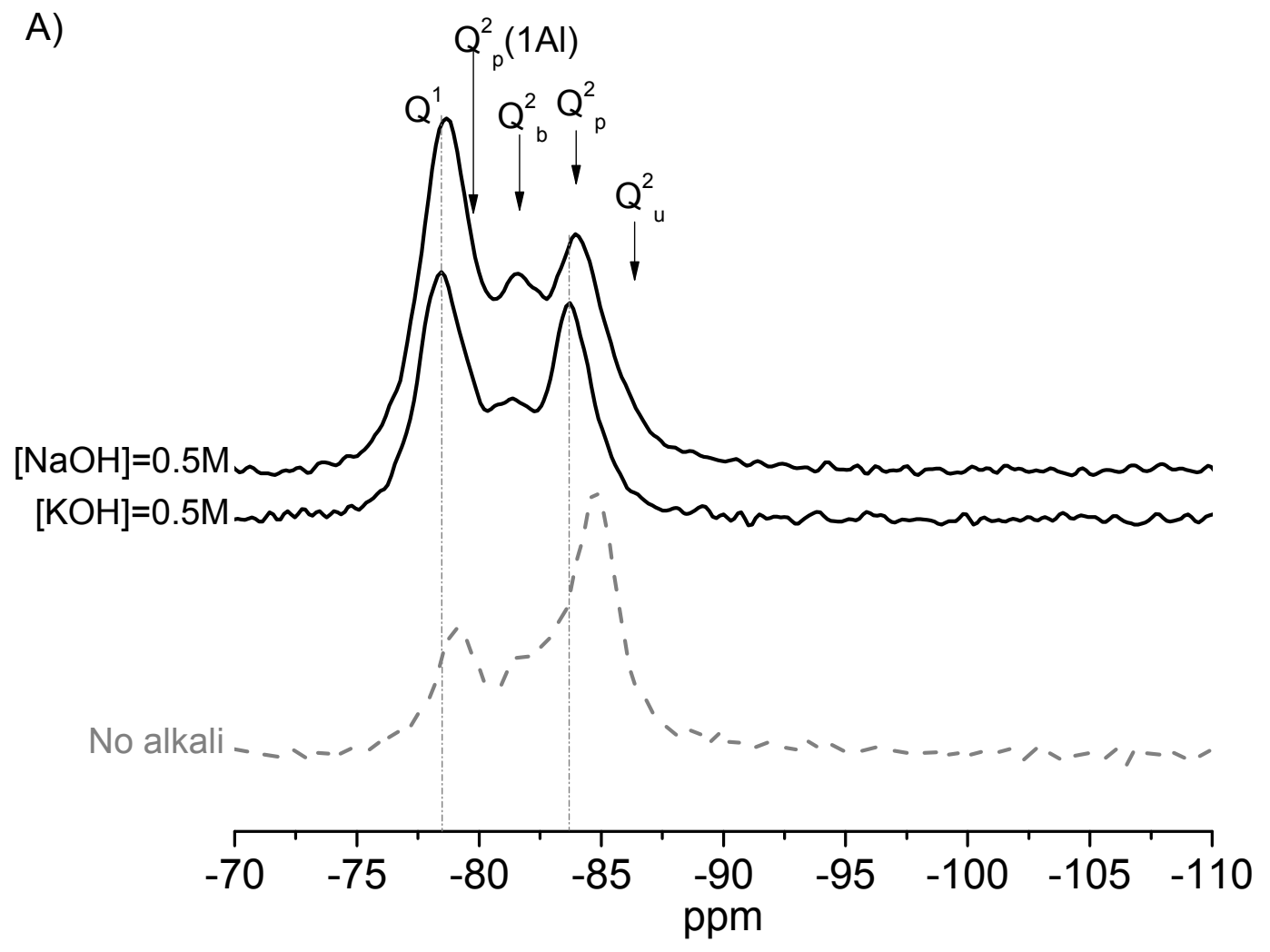

B) C-S-H
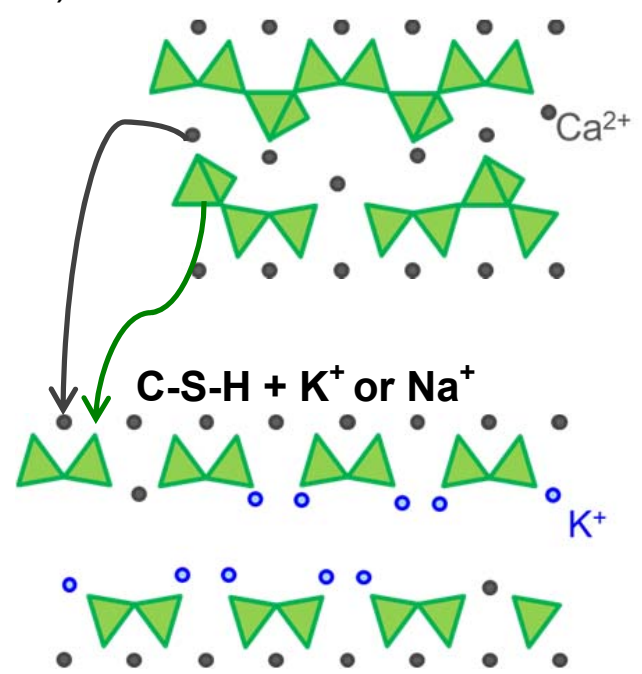

247 Figure 7: A) ${ }^{29} \mathrm{Si}$ MAS NMR spectra of $\mathrm{C}-\mathrm{A}-\mathrm{S}-\mathrm{H}$ with target $\mathrm{Ca} / \mathrm{Si}=1.0$ and $\mathrm{Al} / \mathrm{Si}=0.1$ after 1 year. B)

248 schematic redistribution of charge balancing calcium from the interlayer to the main calcium oxide layer, adapted from Dark circles: calcium; light (blue) circles: K; triangles; silica tetrahedra. (adapted from [4]), 
Table 1: Peak position $( \pm 0.5)$, Relative fractions $( \pm 2)$ of $Q^{n}, A l / S i$ ratio $( \pm 0.01)$ and mean chain length

253 (MCL, $\pm 5 \%$ ) obtained by deconvolution of ${ }^{29} \mathrm{Si}$ MAS NMR spectra, for $\mathrm{C}-\mathrm{S}-\mathrm{H}$ with a target $\mathrm{Ca} / \mathrm{Si}=1.0$.

\begin{tabular}{|c|c|c|c|c|c|c|c|c|c|c|c|c|}
\hline \multirow{2}{*}{$\begin{array}{c}\text { Alkali } \\
\text { concentration }\end{array}$} & \multicolumn{2}{|c|}{$\mathrm{Q}^{1}$} & \multicolumn{2}{|c|}{$Q_{p}^{2}$} & \multicolumn{2}{|c|}{$\mathrm{Q}_{\mathrm{b}}^{2}$} & \multicolumn{2}{|c|}{$\mathrm{Q}_{\mathrm{u}}^{2}$} & \multicolumn{2}{|c|}{$\mathrm{Q}^{2}(1 \mathrm{Al})$} & \multirow[t]{2}{*}{$\mathrm{Al} / \mathrm{Si}$} & \multirow[t]{2}{*}{$\mathrm{MCL}$} \\
\hline & ppm & $\%$ & ppm & $\%$ & ppm & $\%$ & ppm & $\%$ & ppm & $\%$ & & \\
\hline \multicolumn{13}{|l|}{$A l / S i=0.1$} \\
\hline No alkali & -79.1 & 24 & -84.9 & 43 & -83.3 & 18 & -88.3 & 4 & -81.5 & 12 & 0.06 & 9 \\
\hline $0.5 \mathrm{~mol} / \mathrm{L} \mathrm{KOH}$ & -78.4 & 46 & -83.8 & 28 & -82.2 & 10 & -85.5 & 4 & -80.9 & 12 & 0.06 & 5 \\
\hline $0.5 \mathrm{~mol} / \mathrm{L} \mathrm{NaOH}$ & -78.2 & 48 & -84.2 & 25 & -82.7 & 9 & -86.8 & 3 & -81.3 & 15 & 0.08 & 5 \\
\hline
\end{tabular}

\subsection{Effect of alkali hydroxides on the aqueous phase composition}

257 Figure 8 shows the effect of alkali hydroxide on the dissolved calcium, silicon and aluminium 258 concentrations. At all $\mathrm{Ca} / \mathrm{Si}$ ratios, a clear decrease of the calcium concentrations is observed in the 259 presence of potassium hydroxide, while silicon and aluminium concentrations increase. The same 260 tendencies have been observed for C-S-H systems in the presence of different quantities of sodium hydroxide $[2,14]$ and for $\mathrm{C}-\mathrm{A}-\mathrm{S}-\mathrm{H}$ at $\mathrm{Ca} / \mathrm{Si}=1.0$ in the presence of potassium hydroxide [4]. These changes are strongly related to the increase of the $\mathrm{pH}$ values due to the presence of alkali hydroxide. 

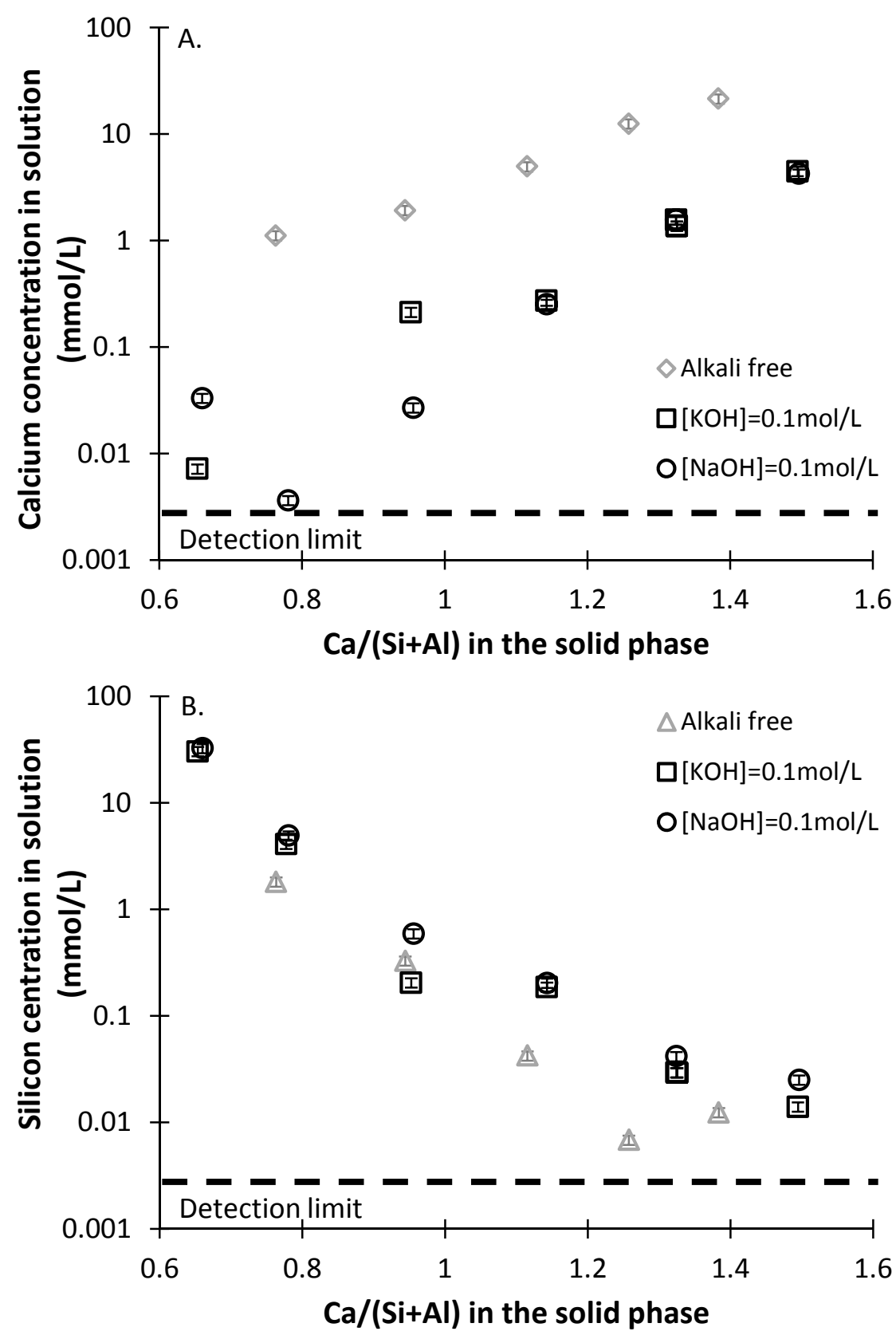


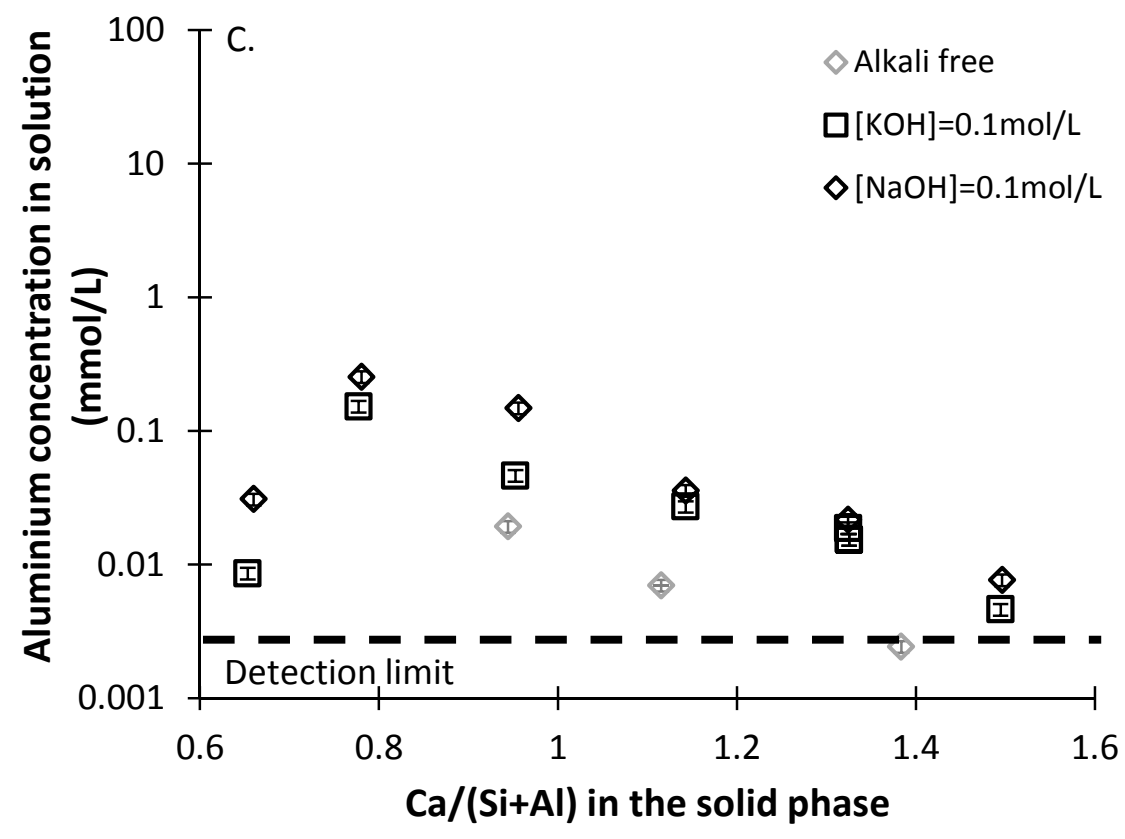

Figure 8: A. Calcium, B. silicon, C. aluminium concentrations in solution as a function of $\mathrm{Ca} / \mathrm{Si}$ ratios in equilibrium with $\mathrm{C}-\mathrm{A}-\mathrm{S}-\mathrm{H}(\mathrm{Al} / \mathrm{Si}=0.05)$ after 1 year.

Figure 9A shows the dissolved concentration of calcium, silicon and aluminium as a function of the measured $\mathrm{pH}$ values. At low $\mathrm{Ca} / \mathrm{Si}$ ratio (target $\mathrm{Ca} / \mathrm{Si}=0.6$ ), the measured $\mathrm{pH}$ values increase from 9.8 in the absence alkali hydroxides to $13.5 \mathrm{in} 0.5 \mathrm{~mol} / \mathrm{L}$ potassium hydroxide. The higher $\mathrm{pH}$ values in the presence of alkali hydroxides increase the silicon and aluminium concentrations, while the calcium concentrations decrease.

The measured dissolved concentrations are compared to thermodynamic predictions using the GEMSelektor code and the simplified CSHQ solid solution model for C-S-H [35], as recent publications [24, $38,59]$ have shown that the presence of a small amount of aluminium has little effect on the observed calcium and silica concentrations. The recently published C-N-A-S-H model of Myers et al. [60] was not used as potassium uptake is not included. The development of a new sublattice solid solution C-K$\mathrm{N}-\mathrm{A}-\mathrm{S}-\mathrm{H}$ thermodynamic model to describe aluminium and alkali uptake in the different structural sites of a tobermorite-like C-S-H structure is beyond the size and scope of the present contribution and will be described elsewhere [61].

Figure 9A shows for $\mathrm{C}-\mathrm{A}-\mathrm{S}-\mathrm{H}$ with $\mathrm{Ca} / \mathrm{Si}=0.6$ in the absence of alkali hydroxides that the measued concentrations agree well with the modelled concentrations and $\mathrm{pH}$ values, which indicates that the system is near saturation with respect to amorphous silica and C-S-H. The addition of alkali 
hydroxides increases the $\mathrm{pH}$ values and leads to undersaturation with respect to amorphous silica, as indicated in Figure 9A. In the presence of more than $0.05 \mathrm{~mol} / \mathrm{L}$ alkali hydroxide, i.e at $\mathrm{pH} \geq 11.5$, lower calcium concentrations are measured than calculated by the CSHQ solid solution model that does not take into account the uptake of alkali by $\mathrm{C}-\mathrm{S}-\mathrm{H}$.

Figure 9B shows that for $\mathrm{C}-\mathrm{A}-\mathrm{S}-\mathrm{H}$ at high $\mathrm{Ca} / \mathrm{Si}$ ratio (target $\mathrm{Ca} / \mathrm{Si}=1.6$ ), the measured $\mathrm{pH}$ increases from 12.5 in the alkali-free systems to 13.6 in the presence of $0.5 \mathrm{~mol} / \mathrm{L}$ potassium hydroxide. The addition of alkali hydroxide leads to a decrease of the dissolved calcium concentrations when portlandite is present, while the silicon and aluminium concentrations increase. As for low $\mathrm{Ca} / \mathrm{Si} \mathrm{C}$-S$\mathrm{H}$, the measured concentrations are compared with calculated concentrations in equilibrium with the CSHQ solid solution model of C-S-H [35]. Figure 9B shows that the system is near saturation with respect to portlandite and $\mathrm{C}-\mathrm{S}-\mathrm{H}$, which is in agreement with the phases observed in the sample (Figure 9B). However, the CSHQ model overestimates the silicon concentrations at higher $\mathrm{pH}$ values, indicating that this model, developed based on the data for alkali-free C-S-H [62], has to be extended for the uptake of alkalis and adapted for high $\mathrm{pH}$ values [61]. 
A) $\mathrm{Ca} / \mathrm{Si}=0.6$

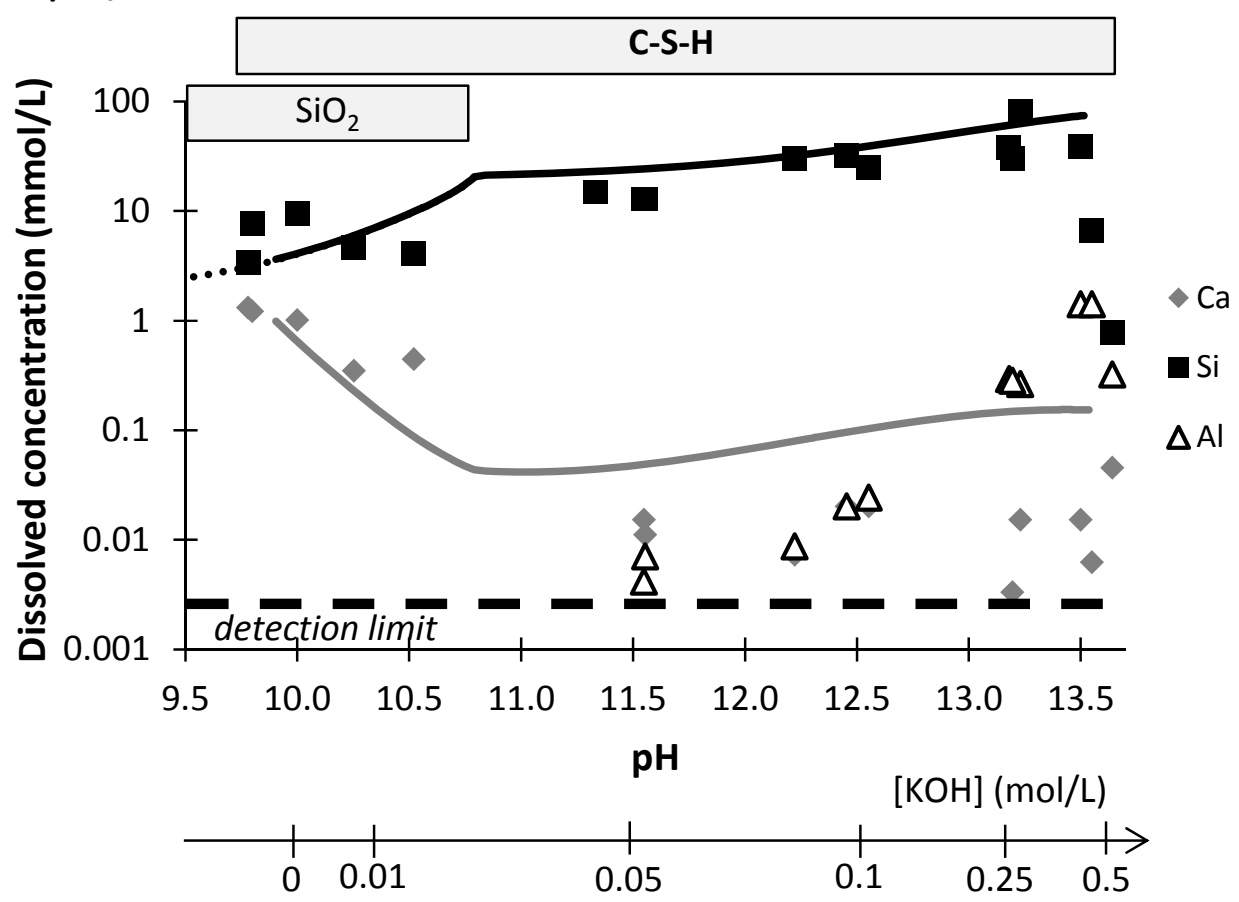

B) $\mathrm{Ca} / \mathrm{Si}=1.6$

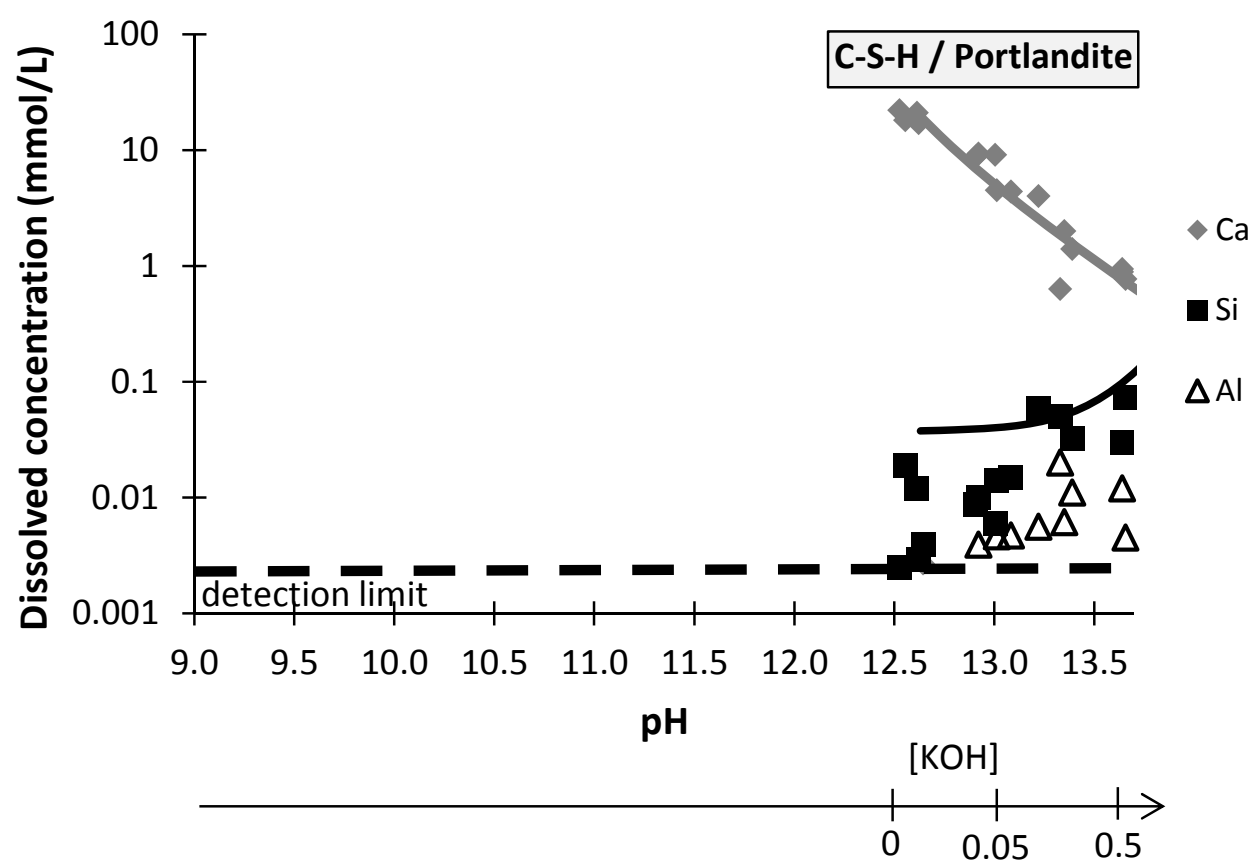

Figure 9: Effect of $\mathrm{pH}$ on total dissolved calcium (diamonds), silicon (triangles) and aluminium (squares) concentration in the presence of $\mathrm{C}-\mathrm{A}-\mathrm{S}-\mathrm{H}(\mathrm{Al} / \mathrm{Si}=0.05)$ at $\mathrm{A}) \mathrm{Ca} / \mathrm{Si}=0.6$ and $\mathrm{B}) 1.6$. For comparison, the calculated calcium (grey curve) and silicon (black curve) concentrations in the presence of amorphous silica, C-S-H and portlandite are indicated (CSHQ model). The boxes used to indicate the stable domain. 


\subsection{Alkali uptake in C-A-S-H}

\subsubsection{Effect of the method of measurement}

311

Figure 10 shows the alkali uptake in C-A-S-H obtained using two different methods: the indirect method based on the decrease of the potassium or sodium concentrations in solutions and mass balance calculations (filtered solution) [11, 20], and the direct method based on a complete dissolution of the filtered solid in $\mathrm{HCl}$. Both methods have advantages and disadvantages. At high alkali concentrations, the indirect determination can be associated with a large error, as the ionic chromatography measurements have about $10 \%$ relative error. The amount of bound alkalis determined by the direct method could be too low due to the washing of the solid with water-ethanol and ethanol that may remove some of the alkali ions present in the diffuse layer, as has been reported for cesium ions by Viallis et al. [63].

Figure 10 compares the measurements of alkali uptake by the indirect (filtered solution) with the direct method (washed sample). The direct method results in a 20 to $50 \%$ lower K/Si ratio, which indicates that at least a part of the loosely bound alkalis is removed by the washing procedure. As the alkali concentrations in pore solutions affect the $\mathrm{pH}$ values and the transport properties in concrete, it is more relevant to determine the $\mathrm{K} / \mathrm{Si}$ ratio by the indirect method that includes the ions present in the diffuse layer. Although the preference was given to the indirect method in this paper, it should be noted that the measurements at high alkali concentrations can be associated with a large relative error as explained above, which can even lead to apparently negative alkali uptake.

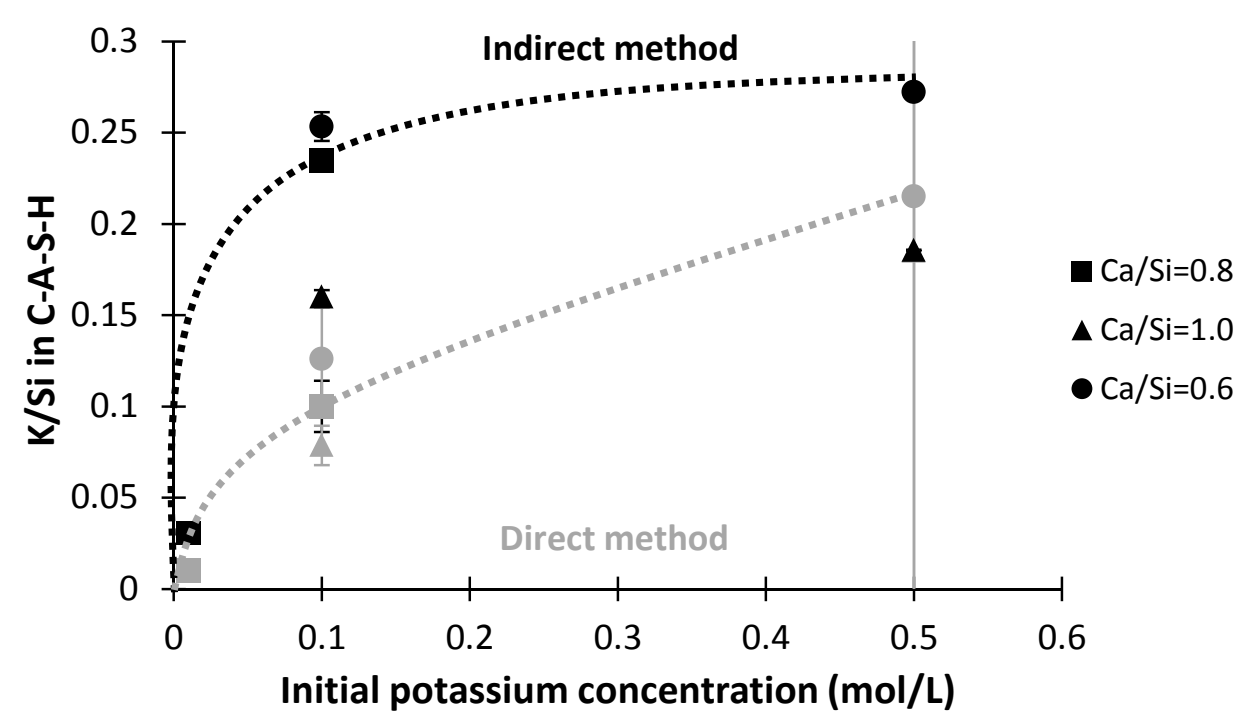


Figure 10: The effect of the measuring method on the alkali/Si ratio in C-A-S-H (AI/Si ratio=0.05). Grey symbols: direct method $=$ analysis of the solid after washing, dark symbols: indirect method $=$ analysis of the filtered solution. Error: $95 \%$ confidence interval. The curves are eye-guides only.

\subsubsection{Effect of aluminium on the alkali uptake}

Figure 11 compares the uptake of potassium in C-S-H and C-A-S-H at different $\mathrm{Ca} / \mathrm{Si}$ ratios. The K/Si ratio is not significantly affected by the presence of aluminium, as previously observed for synthetic CS-H and C-A-S-H [1] and in cement pastes [8]. This is in contrast to observations by Hong and Glasser [20] of an increase in alkali uptake in the presence of aluminium, or Stade [11] who reported a decrease. The scatter of results in the literature could be related either to the significant experimental error associated with the determination of alkali uptake in $\mathrm{C}-\mathrm{S}-\mathrm{H}$ based on the decrease of the dissolved alkali concentrations as in Stade [11] and Hong and Glasser [20] (indirect method), or to the presence of other solids such as amorphous silica, stratlingite or katoite, which can change the silica fraction present in C-S-H. In addition, stratlingite might also bind alkalis, as has been suggested based on the pore solution analysis in calcium sulfoaluminate cement [64]. Unfortunately, neither paper of Stade [11] nor Hong and Glasser [20] reported any analysis of the solid phases formed, so the reasons for the their diverging observations cannot be further clarified.

It has been suggested that the replacement of silica $\left(\mathrm{SiO}_{2}\right)$ by aluminium $\left(\mathrm{AlO}_{2}^{-}\right)$introduces additional negative charge, and thus increase the alkali uptake [20]. However, not only the difference in charge between $\mathrm{Al}^{3+}$ and $\mathrm{Si}^{4+}$ but also the acidity of the hydroxyl groups (=tendency to deprotonate) and the calcium concentrations must also be considered. Recent Monte Carlo simulations of the intrinsic acidity of silanol sites in C-S-H showed that the bridging silica deprotonate below pH 10 (pKa $=6.2$ and 8.6 [65]), resulting in near complete deprotonation to $=\mathrm{SiO}_{2}{ }^{2-}$ at the $\mathrm{pH}$ values $>10$, which results in a negatively charged C-S-H surface as observed by zeta potential measurements [66]. The deprotonation/protonation of aluminium in the bridging sites is presently not well investigated. However, a slightly more negative zeta potential has been measured at low $\mathrm{Ca} / \mathrm{Si}$ ratio in the presence of aluminium [66] and little difference in the presence of more calcium. This small increase in negative charge at low $\mathrm{Ca} / \mathrm{Si}$ does not seem to significantly enhance potassium uptake in C-S-H and C-A-S-H, as shown in Figure 11. 


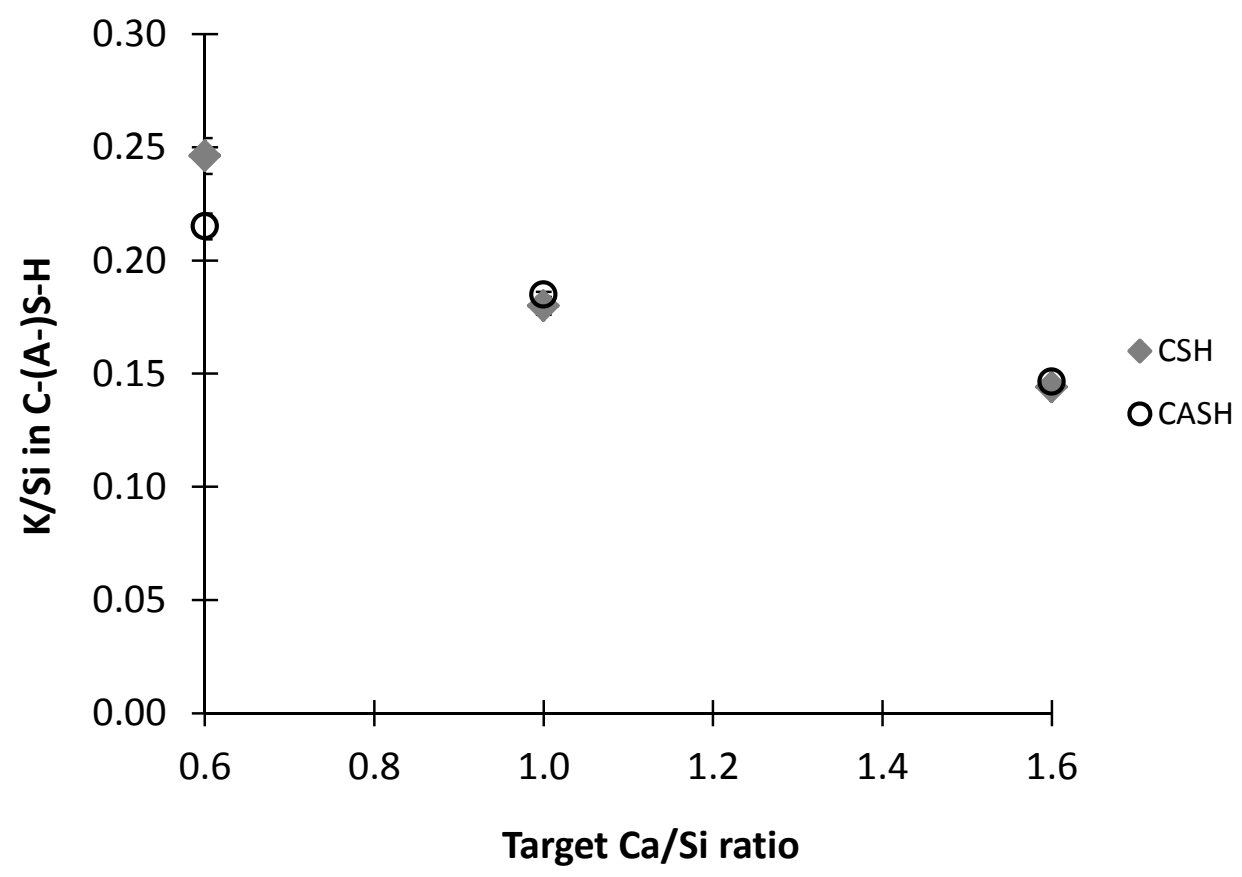

Figure 11: Alkali uptake in C-S-H and C-A-S-H (Al/Si=0.05) in equilibrium with a solution containing $0.5 \mathrm{~mol} / \mathrm{L}[\mathrm{KOH}]$ equilibrated for 182 days. Error: $95 \%$ confidence interval.

\subsubsection{Comparison of potassium uptake with sodium uptake}

The alkali uptake is not influenced by the type of cation. For potassium and sodium similar $(\mathrm{K}$ or $\mathrm{Na}) / \mathrm{Si}$ ratio are observed as shown in Figure 12. In the literature, contradicting findings have been reported with sodium higher than potassium [15, 19], comparable [3,11], and sodium lower than potassium uptake $[1,67]$. In many cases, the difference may be attributed to the error associated with mass balance calculations based on high aqueous concentrations or to the experimental protocol, although no clear tends between the results and the methods could be identified. The scatter of results reported in the literature could also indicate that a number of different mechanisms are responsible for the alkali uptake in $\mathrm{C}-\mathrm{S}-\mathrm{H}$; the results may vary depending on the alkali concentration, the $\mathrm{C}-\mathrm{S}-\mathrm{H}$ composition and the presence of other solids.

375 The maximum $\mathrm{K} / \mathrm{Si}$ and $\mathrm{Na} / \mathrm{Si}$ ratio observed are in the range $0.2-0.3$ for $\mathrm{Ca} / \mathrm{Si}=0.6$ (Figure 11, Figure 12 and Appendix $\mathrm{C}$ ). These values agree with the maximum $\mathrm{Na} / \mathrm{Si}$ and $\mathrm{K} / \mathrm{Si}$ ratios reported by $[11,14]$ 

observed by Bach et al. [1] as shown further below, while Hong et al. [3] report a lower uptake.

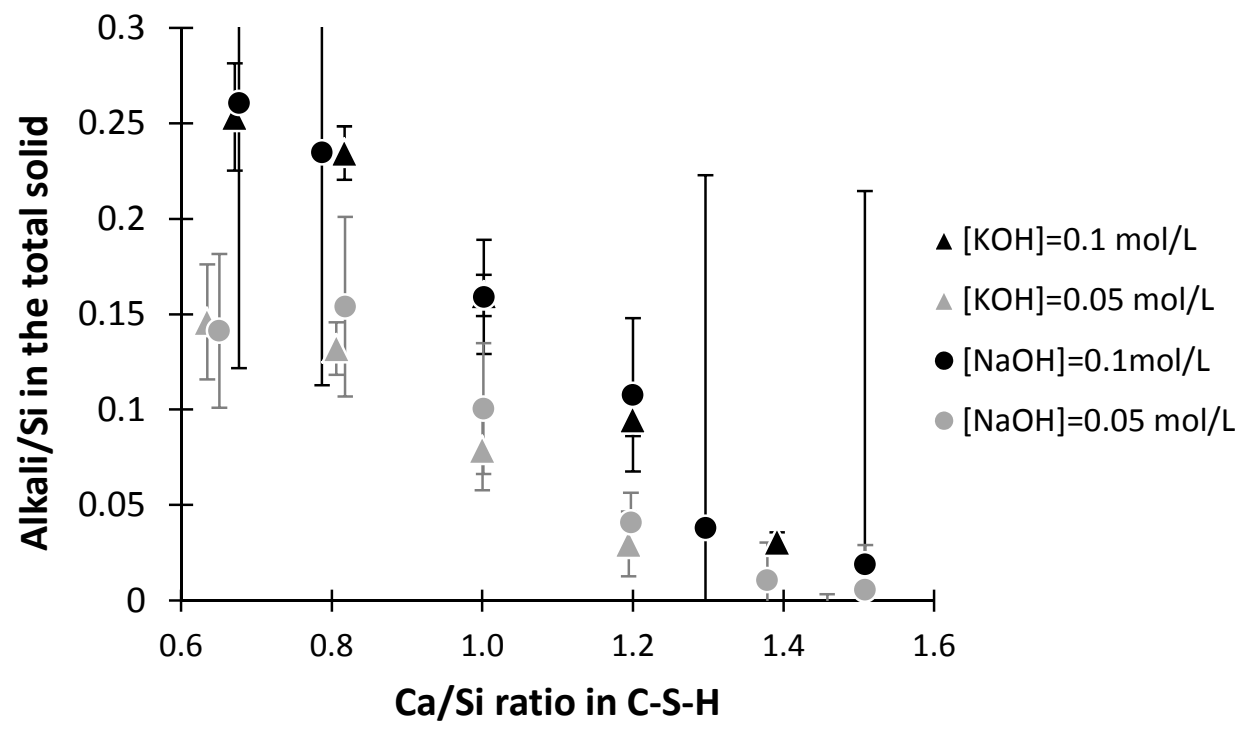

Figure 12: Alkali uptake in $\mathrm{C}-\mathrm{A}-\mathrm{S}-\mathrm{H}(\mathrm{Al} / \mathrm{Si}=0.05)$ after an equilibration time of 182 days. Error: $95 \%$ confidence interval

\subsubsection{Factors influencing alkali uptake in C-A-S-H}

The amount of alkali available is one of the main factors which determine the alkali uptake in C-A-S-H. Figure 12 and Figure $13 \mathrm{~A}$ shows that the alkali uptake in C-A-S-H increases as a function of the aqueous alkali concentrations. At low alkali concentrations, a linear relation between the initial potassium concentrations and the $\mathrm{K} / \mathrm{Si}$ in $\mathrm{C}-\mathrm{A}-\mathrm{S}-\mathrm{H}$ is observed, while at higher alkali concentrations, 250 and $500 \mathrm{mmol} / \mathrm{L}$, the alkali uptake increases much less strongly than the dissolved concentrations in solution. This trend is characteristic for an adsorption isotherm and this behaviour can be described e.g. by a Langmuir isotherm: $\theta_{i}=\alpha \cdot C_{i} /\left(1+\alpha \cdot C_{i}\right)$ where $\theta_{i}$ is the surface fractional coverage of i-th component, $C_{i}$ is its dissolved aqueous concentration, and $\alpha$ is the Langmuir adsorption constant. At low alkali concentrations, the amount of potassium or sodium bound in $\mathrm{C}-\mathrm{S}-\mathrm{H}$ is small in comparison 

sodium ions is comparable to the total amount of deprotonated silica.

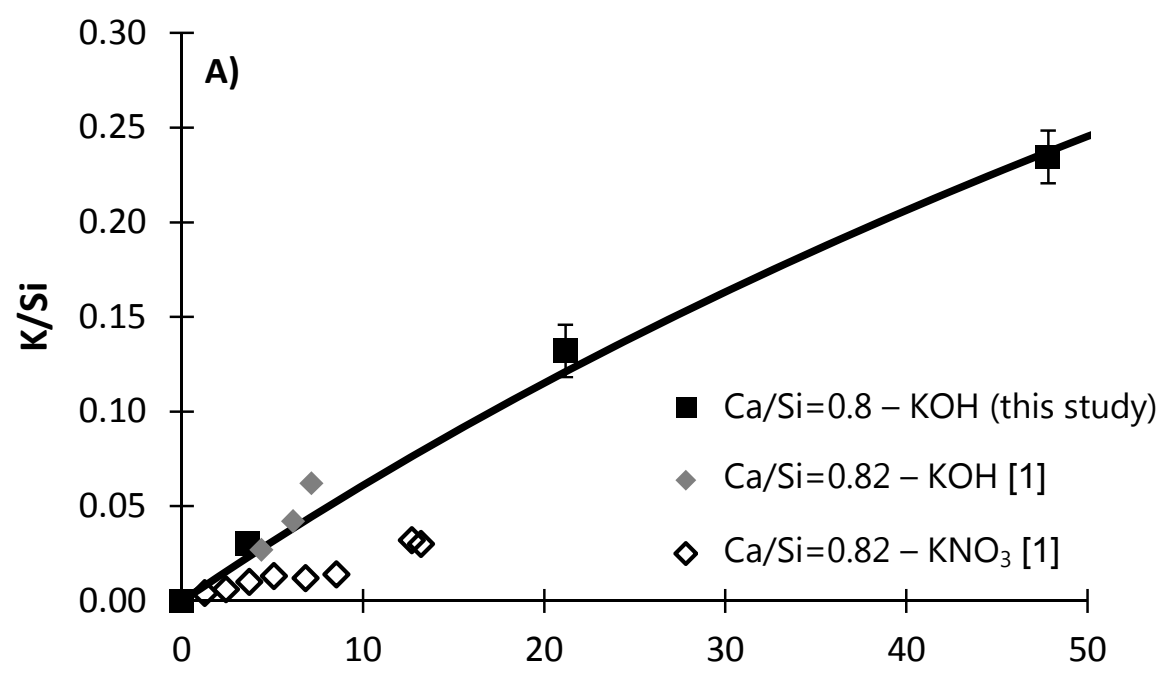

Dissolved aqueous alkali concentration (mmol/L)

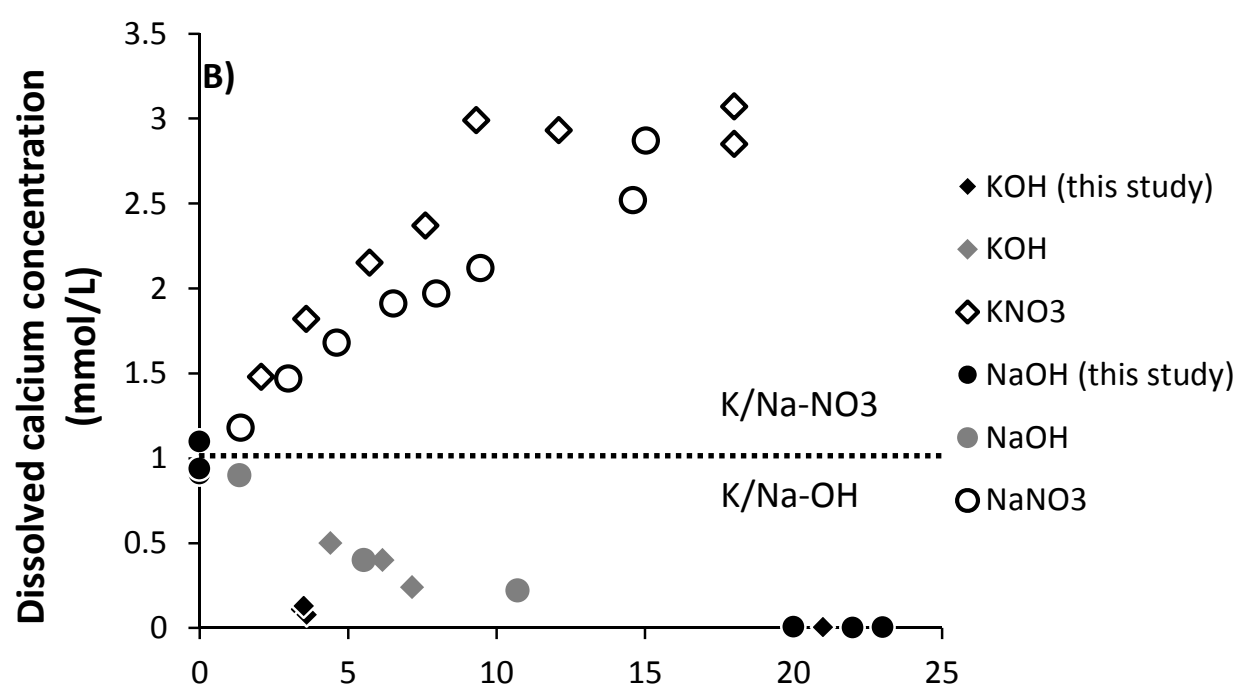

Dissolved potassuim or sodium concentration (mmol/L)

Figure 13: A) Potassium $(\mathrm{KOH})$ uptake on $\mathrm{C}-\mathrm{A}-\mathrm{S}-\mathrm{H}$ with $\mathrm{Ca} / \mathrm{Si}=0.8$ and $\mathrm{Al} / \mathrm{Si}=0.05$ compared with potassium uptake in $\mathrm{C}-\mathrm{S}-\mathrm{H}$ with similar $\mathrm{Ca} / \mathrm{Si}$ ratio in $\mathrm{KOH}$ or $\mathrm{KNO}_{3}$ [1]. Error: $95 \%$ confidence interval. The curve represents the Langmuir equation with $\alpha=0.0065$. B) Effect of alkali on the calcium concentrations in the presence of alkali hydroxide (data from this paper and from Bach et al. [1]). Solutions in equilibrium with synthetic $\mathrm{C}-\mathrm{S}-\mathrm{H}$ and $\mathrm{C}-\mathrm{A}-\mathrm{S}-\mathrm{H}(\mathrm{Ca} /(\mathrm{Si}+\mathrm{Al})=0.8-0.85)$

Figure 14 shows the measured potassium uptake as a function of the $\mathrm{Ca} / \mathrm{Si}$ ratio after 91,182 and 365 days. The $\mathrm{Ca} / \mathrm{Si}$ ratio strongly influences the alkali uptake in $\mathrm{C}-\mathrm{S}-\mathrm{H}$ as visible in Figure 14 and as 


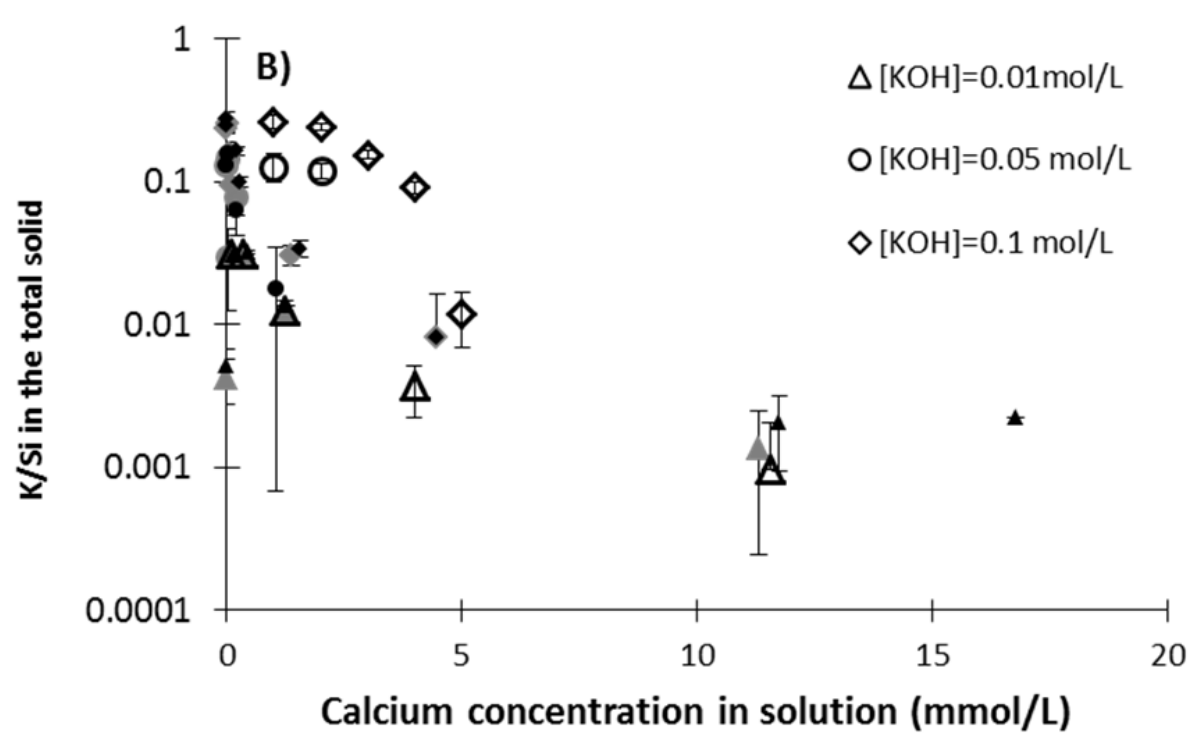
concentrations; maximum $\mathrm{Na} / \mathrm{Si}$ and $\mathrm{K} / \mathrm{Si}$ ratios reported are in the range $0.3-0.5[11,14]$.

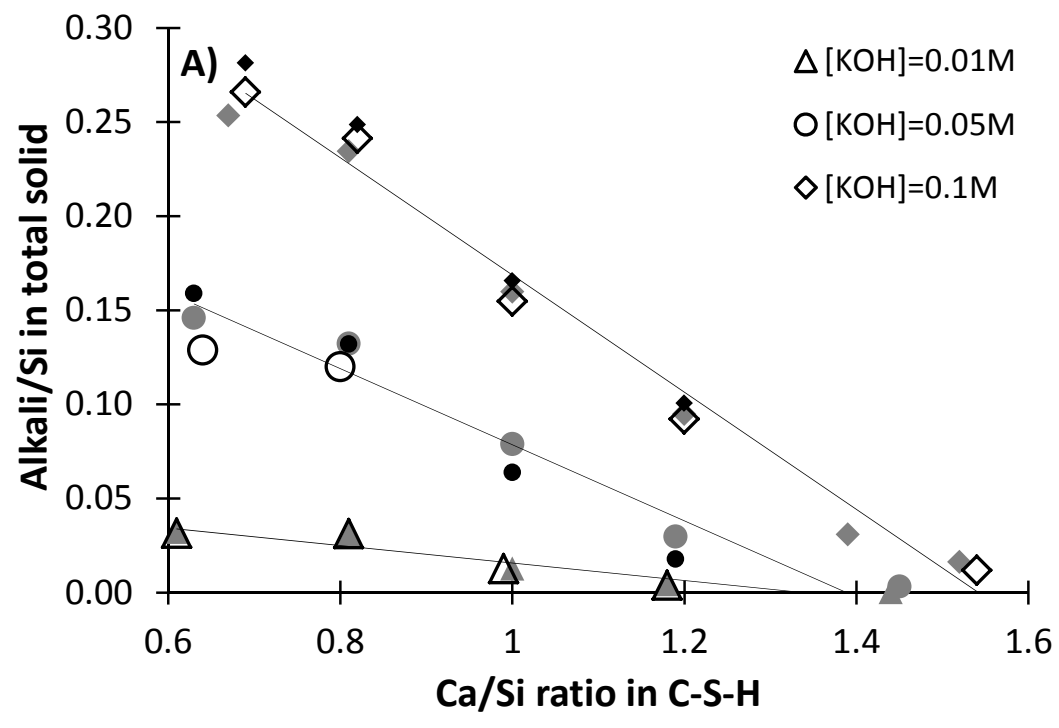

previously reported by different authors $[3,11,14]$. Both alkali and calcium ions can compensate the negative charge of $\mathrm{C}-\mathrm{S}-\mathrm{H}$ surfaces: $\mathrm{SiO}^{-}+\mathrm{K}^{+} \rightarrow \mathrm{Si}-\mathrm{OK}, \mathrm{SiO}^{-}+\mathrm{Ca}^{2+} \rightarrow \mathrm{Si}^{-\mathrm{OCa}^{+}}$, as shown by $\mathrm{Labbez}^{-}$ et al. [57] experimentally and by Monte Carlo simulations. Divalent cations such as $\mathrm{Ca}^{2+}$ are preferentially adsorbed compared to monovalent cations such as $\mathrm{Na}^{+}$or $\mathrm{K}^{+}$due to the stronger electrostatic interactions [58]. Thus, high dissolved calcium concentrations can inhibit the alkali uptake. As a consequence, the alkali uptake by high $\mathrm{Ca} / \mathrm{Si} \mathrm{C}-\mathrm{S}-\mathrm{H}$, which is in equilibrium with high calcium concentrations, is low $[3,11,14,57]$ as shown in Figure 14. Even if the alkali concentration is much higher than the calcium concentration, two orders of magnitude in the case of the data presented in Figure $14 \mathrm{~b}$, calcium concentrations still have a very strong influence on the alkali uptake. In contrast, the alkali uptake is strongly enhanced in presence of low Ca/Si C-S-H and thus low dissolved calcium 
Figure 14: Potassium uptake in $\mathrm{C}-\mathrm{A}-\mathrm{S}-\mathrm{H}(\mathrm{Al} / \mathrm{Si}=0.05)$ plotted versus $\mathrm{A})$ the $\mathrm{Ca} / \mathrm{Si}$ ratio in the $\mathrm{C}-\mathrm{A}-\mathrm{S}-\mathrm{H}$ and B) measured calcium concentrations. Empty symbol: 91 days, grey symbol: 182 days, dark symbol: 365 days equilibration time. Error: 95\% confidence interval. The curves are eye-guides only.

The addition of alkali hydroxide leads to a strong increase of $\mathrm{pH}$ and lowers the calcium concentrations as seen in Figure 9 and Figure 13B. If not alkali hydroxide, but alkali nitrate or alkali chloride solutions are added, the $\mathrm{pH}$ does not change significantly, and an increase of the calcium concentrations is observed at higher alkali concentrations (Figure 13B) as some of the calcium ions in the interlayer of the C-S-H are replaced by alkali ions.

The addition of alkali hydroxide lowers not only dissolved calcium concentrations but leads also to more de-protonation of silanol sites and, thus, to more negatively charged C-S-H surface $[4,57,68]$. Both factors contribute to an increased binding of sodium and potassium in solutions containing hydroxides compared to solutions with nitrates or chlorides, as shown by the higher alkali/Si ratio for C-A-S-H in Figure 14. The presence of charge-balancing potassium or sodium instead of calcium results in shorter silica chain lengths and a decrease of the "dreierketten" chain length observed by ${ }^{29} \mathrm{Si} \mathrm{NMR}$ as shown in Figure 7, and to a decrease of the basal spacing (Figure 6, [1]) .

Studies using ${ }^{23} \mathrm{Na}-\mathrm{NMR}[23,69,70]$ indicate two different environments for alkali uptake in C-S-H. At all $\mathrm{Ca} / \mathrm{Si}$ ratios, a sharp sodium signal is observed, which was assigned to highly symmetrically bound $\mathrm{Na}$ or to mobile $\mathrm{Na}$ or $\mathrm{NaCl}$. At low $\mathrm{Ca} / \mathrm{Si}$ ratio, an additional broad sodium signal at $\approx-10 \mathrm{ppm}$ is observed, indicating a low-mobility, "bound" sodium [23]. The fraction of "bound" sodium is observed to decrease strongly with increasing $\mathrm{Ca} / \mathrm{Si}$ ratio in the presence of relatively low Na concentration (total $\mathrm{Na} / \mathrm{Si}=0.1[23])$. 


\section{Conclusions}

445 The alkali uptake in C-S-H and C-A-S-H depends strongly on the $\mathrm{Ca} / \mathrm{Si}$ ratio. At high $\mathrm{Ca} / \mathrm{Si}$ ratios, very little alkalis are taken up, while a decrease of the $\mathrm{Ca} / \mathrm{Si}$ ratio results in an increase of the alkali uptake. The alkali uptake is also influenced by the dissolved alkali concentrations. For a C-A-S-H (Al/Si=0.05) with nominal $\mathrm{Ca} / \mathrm{Si}=0.6$, the molar $\mathrm{K} / \mathrm{Si}$ ratio in $\mathrm{C}-\mathrm{A}-\mathrm{S}-\mathrm{H}$ raises from 0.03 in $10 \mathrm{mmol} / \mathrm{L} \mathrm{KOH}$ to 0.27 in $500 \mathrm{mmol} / \mathrm{L} \mathrm{KOH}$. The presence of aluminium and the hydration time have no significant effect on the alkali uptake, and no significant difference between potassium and sodium uptake in C-S-H was observed.

The addition of alkali hydroxides increases the $\mathrm{pH}$ values and lowers the calcium concentrations, while in alkali nitrate or chloride solutions little $\mathrm{pH}$ change but higher calcium concentrations were observed. The comparison of alkali uptake shows that, at a constant target $\mathrm{Ca} / \mathrm{Si}$ ratio, more alkalis are bound in alkali hydroxide solutions due to the lower calcium concentration than in alkali nitrate or chloride solutions. Both calcium and alkali ions are assumed to be taken up in the interlayer and at the surface of $\mathrm{C}-\mathrm{S}-\mathrm{H}$ to compensate the negative charge of the $\mathrm{C}-\mathrm{S}-\mathrm{H}$ caused by the deprotonation of the silanol groups. In this process, the divalent calcium ion is strongly preferred in comparison to monovalent alkali ions, such that the alkali sorption is supressed in the presence of higher aqueous calcium concentrations as present at high $\mathrm{Ca} / \mathrm{Si}$ ratios. Thus, a higher alkali uptake is observed in the presence of low calcium concentrations, such as those in equilibrium with low-Ca/Si C-S-H or in the presence of high alkali hydroxides concentration.

The presence of sodium and potassium in the interlayer does not significantly change the structure of $\mathrm{C}-\mathrm{S}-\mathrm{H}$, but can at high concentrations decrease the interlayer distance in C-A-S-H and shorten the silica chain length as observed by ${ }^{29} \mathrm{Si}$ NMR, thus indicating the uptake of alkali in the interlayer space of C-S-H.

\section{Acknowledgements}

The financial support of Swiss National Foundation Sinergia grant $n^{\circ} 130419$ is gratefully acknowledged. The authors would like to thank Daniel Rentsch, Salaheddine Alahrache, Angela Steffen, Luigi Brunetti, Ellina Bernard and Boris Ingold for the helpful advice and support during the measurements and to Jørgen Skibsted, Andre Nonat, Céline Cau Dit Coumes, Gwenn Le Saout and 
473 Gilles Plusquellec for helpful discussions. The thanks are extended to the reviewers, whose comments 474 helped to improve the manuscript. 


\section{Appendixes}

476 Appendix A Samples studied: mixing proportions used to prepare C-S-H and C-A-S-H (in g per

$47790 \mathrm{~mL}$ of solution).

\begin{tabular}{rccc}
\hline \multicolumn{3}{c}{ Initial composition } \\
$\mathrm{Ca} / \mathrm{Si}$ & $\mathrm{CaO}(\mathrm{g})$ & $\mathrm{SiO}_{2}(\mathrm{~g})$ & $\mathrm{CaO} . \mathrm{Al}_{2} \mathrm{O}_{3}(\mathrm{~g})$ \\
\hline $\mathbf{A l} / \mathbf{S i} \mathbf{0}$ & & & \\
0.6 & 0.718 & 1.282 & \\
1.0 & 0.966 & 1.034 & \\
1.6 & 1.198 & 0.802 & \\
\hline $\mathbf{A l} / \mathbf{S i} \mathbf{= 0 . 0 5}$ & & & 0.082 \\
0.6 & 0.670 & 1.248 & 0.074 \\
0.8 & 0.809 & 1.118 & 0.067 \\
1.0 & 0.921 & 1.012 & 0.061 \\
1.2 & 1.014 & 0.925 & 0.056 \\
1.4 & 1.093 & 0.851 & 0.052 \\
1.6 & 1.159 & 0.789 & 0.130 \\
\hline $\mathbf{A l} / \mathbf{S i} \mathbf{0} \mathbf{0 . 1}$ & & &
\end{tabular}

478

Appendix B Aqueous dissolved concentrations

480

* Normalized potassium or sodium ((Measured dissolved potassium or sodium concentration target initial concentration)/ Measured initial alkali concentration (from the blank solution)), -: not observed.

C-A-S-H (Al/Si=0.05)

\begin{tabular}{|c|c|c|c|c|c|c|c|c|}
\hline $\begin{array}{c}\text { Inital alkali } \\
\text { concentration }\end{array}$ & $\begin{array}{l}\text { Time } \\
\text { (days) }\end{array}$ & Si & $\mathrm{Ca}$ & $\begin{array}{l}\mathrm{Al} \\
(\mathrm{mmol} / \mathrm{L})\end{array}$ & $\mathrm{K}^{*}$ & $\mathrm{Na}^{*}$ & $\mathrm{OH}$ & $\begin{array}{c}\mathrm{pH} \\
-\end{array}$ \\
\hline
\end{tabular}

$\begin{array}{ccccccccc}\text { Ca/Si=0.6 } & & & & & & & & \\ \text { Alkali free } & 91 & 9.4 & 1.0 & \leq 0.0037 & - & - & 0.100 & 10.0 \\ & 182 & 7.7 & 1.2 & \leq 0.0037 & - & - & 0.050 & 9.8 \\ & 364 & 3.4 & 1.3 & \leq 0.0037 & - & - & 0.048 & 9.8 \\ {[\mathrm{KOH}]=0.01 \mathrm{M}} & 91 & 4.6 & 0.346 & \leq 0.0037 & 2.6 & - & 0.13 & 10.3 \\ & 182 & 4.1 & 0.385 & \leq 0.0037 & 2.6 & 0.1 & 0.00 & 10.3 \\ & 364 & 4.1 & 0.440 & \leq 0.0037 & 2.5 & 0.07 & 0.23 & 10.5 \\ {[\mathrm{KOH}]=0.05 \mathrm{M}} & 91 & 15 & \leq 0.0025 & \leq 0.0037 & 15 & 0.15 & 1.4 & 11.3 \\ & 182 & 13 & 0.015 & 0.0041 & 16 & 0.16 & 2.4 & 11.5 \\ & 364 & 13 & 0.011 & 0.0070 & 14 & 0.15 & 2.4 & 11.6 \\ {[\mathrm{KOH}]=0.1 \mathrm{M}} & 91 & 32 & 0.020 & 0.020 & 44 & 0.39 & 21 & 12.5 \\ & 364 & 25 & 0.020 & 0.024 & 43 & 0.37 & 26 & 12.6 \\ {[\mathrm{KOH}]=0.25 \mathrm{M}} & 91 & 30 & 0.0072 & 0.0086 & 43 & 0.38 & 14 & 12.2 \\ {[\mathrm{KOH}]=0.5 \mathrm{M}} & 364 & 30 & 0.0033 & 0.28 & 185 & 1.5 & 139 & 13.2 \\ & 91 & 39 & 0.015 & 1.4 & 445 & 2.7 & 319 & 13.5\end{array}$




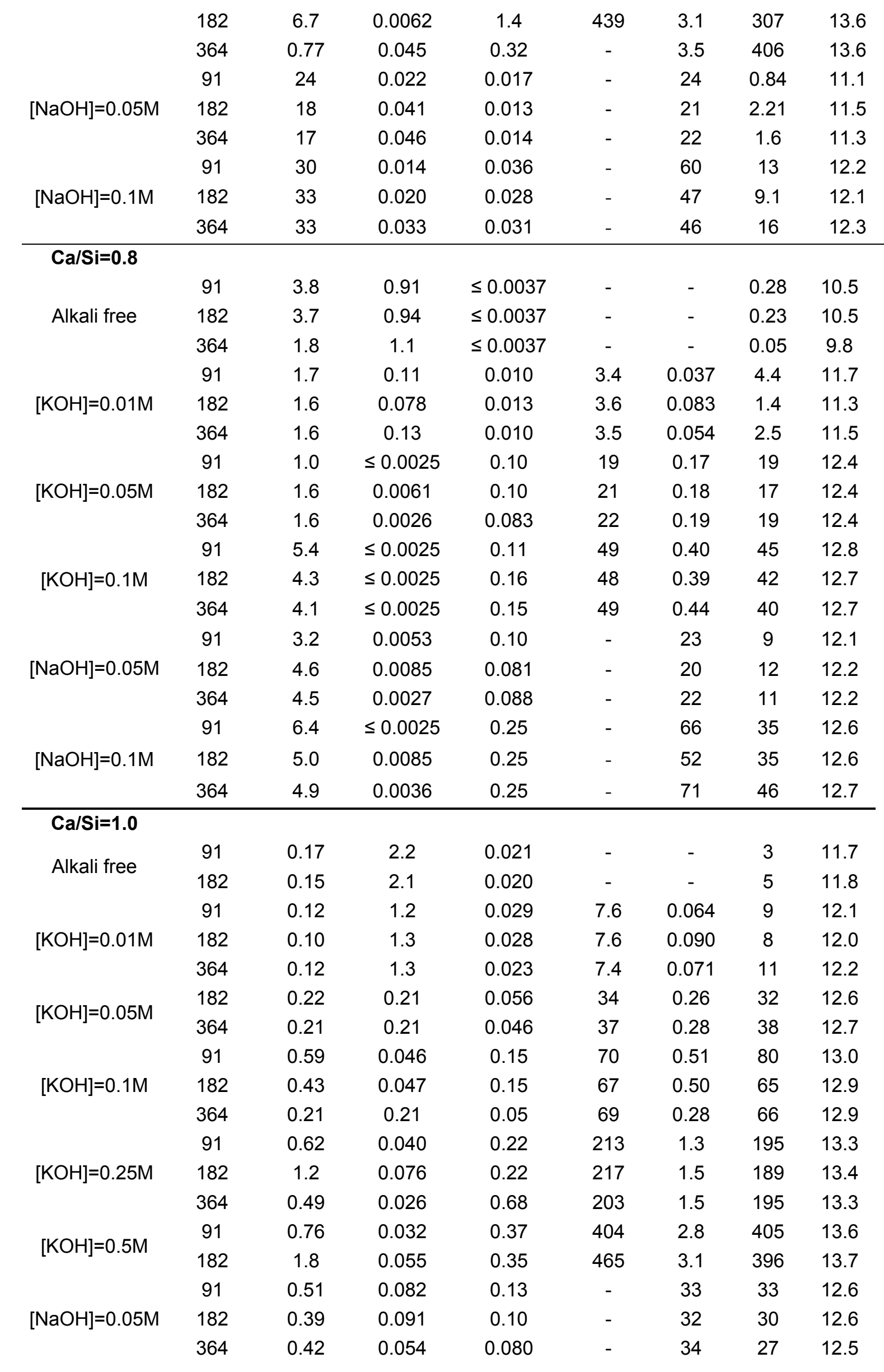




\begin{tabular}{|c|c|c|c|c|c|c|c|c|}
\hline$[\mathrm{NaOH}]=0.1 \mathrm{M}$ & $\begin{array}{l}182 \\
364\end{array}$ & $\begin{array}{l}0.46 \\
0.59\end{array}$ & $\begin{array}{l}0.061 \\
0.027\end{array}$ & $\begin{array}{l}0.18 \\
0.15\end{array}$ & - & $\begin{array}{l}70 \\
74\end{array}$ & 100 & $\begin{array}{l}13.1 \\
129\end{array}$ \\
\hline \multicolumn{9}{|l|}{$\mathrm{Ca} / \mathrm{Si}=1.2$} \\
\hline \multirow{3}{*}{ Alkali free } & 91 & 0.10 & 4.4 & 0.011 & - & - & 0.22 & 11.9 \\
\hline & 182 & 0.17 & 4.2 & 0.0066 & - & - & 9.4 & 12.1 \\
\hline & 364 & 0.042 & 5.0 & 0.0070 & - & - & 9.4 & 12.1 \\
\hline \multirow{3}{*}[\mathrm{KOH}]{$=0.01 \mathrm{M}$} & 91 & 0.031 & 4.0 & $\leq 0.0037$ & 9.3 & 0.1 & 16 & 12.3 \\
\hline & 182 & 0.029 & 4.0 & $\leq 0.0037$ & 9.3 & 0.1 & 14 & 12.3 \\
\hline & 364 & 0.031 & 3.9 & $\leq 0.0037$ & 9.1 & 0.1 & 18 & 12.4 \\
\hline \multirow{2}{*}[\mathrm{KOH}]{$=0.05 \mathrm{M}$} & 182 & 0.057 & 1.1 & 0.016 & 45 & 0.30 & 44 & 12.8 \\
\hline & 364 & 0.072 & 1.0 & 0.020 & 47 & 0.33 & 48 & 12.8 \\
\hline \multirow{3}{*}[\mathrm{KOH}]{$=0.1 \mathrm{M}$} & 91 & 0.26 & 0.21 & 0.035 & 83 & 0.58 & 102 & 13.1 \\
\hline & 182 & 0.18 & 0.23 & 0.032 & 82 & 0.56 & 77 & 13.0 \\
\hline & 364 & 0.19 & 0.27 & 0.027 & 83 & 0.64 & 78 & 12.9 \\
\hline \multirow{3}{*}[\mathrm{KOH}]{$=0.25 \mathrm{M}$} & 91 & 0.029 & 0.52 & 0.015 & 236 & 1.1 & 217 & 13.3 \\
\hline & 182 & $\leq 0.0036$ & 2.1 & 0.065 & 257 & 1.8 & 212 & 13.3 \\
\hline & 364 & 0.10 & 0.37 & 0.039 & 206 & 1.7 & 215 & 13.4 \\
\hline \multirow{3}{*}[\mathrm{NaOH}]{$=0.05 \mathrm{M}$} & 91 & 0.14 & 0.54 & 0.027 & & 41 & 40 & 12.7 \\
\hline & 182 & 0.11 & 0.62 & 0.023 & - & 43 & 41 & 12.7 \\
\hline & 364 & 0.11 & 0.55 & 0.018 & - & 44 & 36 & 12.7 \\
\hline \multirow{2}{*}[\mathrm{NaOH}]{$=0.1 \mathrm{M}$} & 182 & 0.19 & 0.24 & 0.041 & - & 81 & 69 & 12.9 \\
\hline & 364 & 0.20 & 0.25 & 0.036 & - & 86 & 89 & 13.0 \\
\hline \multicolumn{9}{|l|}{$\mathrm{Ca} / \mathrm{Si}=1.4$} \\
\hline \multirow{3}{*}{ Alkali free } & 91 & 0.0079 & 13 & 0.0059 & - & - & 16 & 12.3 \\
\hline & 182 & 0.16 & 12 & 0.0039 & - & - & 29 & 12.6 \\
\hline & 364 & 0.0069 & 13 & $\leq 0.0037$ & - & - & 18 & 12.4 \\
\hline \multirow{3}{*}[\mathrm{KOH}]{$=0.01 \mathrm{M}$} & 91 & 0.0061 & 12 & $\leq 0.0037$ & 9.8 & 0.076 & 29 & 12.5 \\
\hline & 182 & 0.0051 & 11 & $\leq 0.0037$ & 9.8 & 0.079 & 25 & 12.5 \\
\hline & 364 & 0.0059 & 12 & $\leq 0.0037$ & 9.7 & 0.084 & 31 & 12.6 \\
\hline \multirow{3}{*}[\mathrm{KOH}]{$=0.05 \mathrm{M}$} & 91 & 0.0065 & 6.7 & 0.0060 & 51 & 0.28 & 76 & 13.0 \\
\hline & 182 & 0.0092 & 6.8 & 0.0041 & 51 & 0.33 & 58 & 12.9 \\
\hline & 364 & 0.010 & 6.8 & $\leq 0.0037$ & 51 & 0.35 & 60 & 12.9 \\
\hline \multirow{3}{*}[\mathrm{KOH}]{$=0.1 \mathrm{M}$} & 182 & 0.029 & 1.4 & 0.015 & 95 & 0.73 & 90 & 13.1 \\
\hline & 364 & 0.029 & 1.6 & 0.019 & 95 & 0.76 & 89 & 13.0 \\
\hline & 91 & 0.025 & 3.4 & 0.0084 & - & 50 & 50 & 12.8 \\
\hline \multirow[t]{3}{*}[\mathrm{NaOH}]{$=0.05 \mathrm{M}$} & 182 & 0.023 & 3.5 & 0.013 & - & 48 & 55 & 12.8 \\
\hline & 364 & 0.024 & 3.1 & 0.012 & - & 52 & 45 & 12.7 \\
\hline & 91 & 0.031 & 1.5 & 0.017 & - & 130 & 89 & 13.0 \\
\hline \multirow[t]{2}{*}[\mathrm{NaOH}]{$=0.1 \mathrm{M}$} & 182 & 0.026 & 1.5 & 0.017 & - & 94 & 100 & 13.1 \\
\hline & 364 & 0.042 & 1.6 & 0.022 & - & 99 & 107 & 13.1 \\
\hline \multicolumn{9}{|l|}{$\mathrm{Ca} / \mathrm{Si}=1.6$} \\
\hline \multirow{3}{*}{ Alkali free } & 91 & $\leq 0.0036$ & 22 & 0.002 & - & - & 29 & 12.5 \\
\hline & 182 & 0.019 & 18 & $\leq 0.0037$ & - & - & 26 & 12.6 \\
\hline & 364 & 0.012 & 21 & $\leq 0.0037$ & - & - & 30 & 12.6 \\
\hline$[\mathrm{KOH}]=0.01 \mathrm{M}$ & 91 & 0.0039 & 17 & $\leq 0.0037$ & 10 & 0.084 & 39 & 12.6 \\
\hline
\end{tabular}




\begin{tabular}{ccccccccc} 
& 182 & $\leq 0.0036$ & 14 & $\leq 0.0037$ & 10 & 0.084 & 34 & 12.6 \\
& 364 & $\leq 0.0036$ & 17 & $\leq 0.0037$ & 9.7 & 0.077 & 34 & 12.6 \\
{$[\mathrm{KOH}]=0.05 \mathrm{M}$} & 91 & 0.0059 & 9.1 & $\leq 0.0037$ & 53 & 0.26 & 80 & 13.0 \\
& 182 & 0.0087 & 8.8 & $\leq 0.0037$ & 50 & 0.33 & 63 & 12.9 \\
& 364 & 0.010 & 9.3 & 0.0039 & 51 & 0.33 & 65 & 12.9 \\
{$[\mathrm{KOH}]=0.1 \mathrm{M}$} & 91 & 0.058 & 4.0 & 0.0056 & 98 & 0.67 & 137 & 13.2 \\
& 182 & 0.015 & 4.4 & 0.0047 & 97 & 0.66 & 97 & 13.1 \\
{$[\mathrm{KOH}]=0.25 \mathrm{M}$} & 364 & 0.014 & 4.5 & 0.0046 & 99 & 0.69 & 97 & 13.0 \\
& 91 & $\leq 0.0036$ & 2.0 & 0.0061 & 271 & 1.3 & 236 & 13.4 \\
& 362 & 0.050 & 0.63 & 0.020 & 241 & 1.7 & 212 & 13.3 \\
{$[\mathrm{KOH}]=0.5 \mathrm{M}$} & 91 & $\leq 0.032$ & 1.4 & 0.011 & 191 & 1.8 & 224 & 13.4 \\
& 182 & 0.030 & 0.94 & $\leq 0.0037$ & 552 & 3.6 & 441 & 13.6 \\
& 364 & 0.072 & 0.77 & 0.0045 & 562 & 3.4 & 421 & 13.7 \\
{$[\mathrm{NaOH}]=0.05 \mathrm{M}$} & 91 & 0.0088 & 8.8 & 0.0063 & - & 52 & 61 & 12.9 \\
& 182 & 0.012 & 6.6 & 0.0056 & - & 49 & 67 & 12.9 \\
& 364 & 0.022 & 7.9 & 0.0054 & - & 53 & 54 & 12.8 \\
{$[\mathrm{NaOH}]=0.1 \mathrm{M}$} & 91 & 0.016 & 4.4 & 0.0081 & - & 134 & 107 & 13.1 \\
& 182 & 0.013 & 4.5 & 0.0089 & - & 97 & 109 & 13.1 \\
& 364 & 0.025 & 4.2 & 0.0077 & - & 103 & 113 & 13.1 \\
\hline
\end{tabular}

484

485

C-A-S-H (AI/Si=0.1)

\begin{tabular}{lcccccccc}
\hline $\begin{array}{c}\text { Inital alkali } \\
\text { concentration }\end{array}$ & $\begin{array}{c}\text { Time } \\
\text { (days) }\end{array}$ & $\mathrm{Si}$ & $\mathrm{Ca}$ & $\begin{array}{c}\mathrm{Al} \\
(\mathrm{mmol} / \mathrm{L})\end{array}$ & $\mathrm{K}^{*}$ & $\mathrm{Na}^{*}$ & $\mathrm{OH}$ & $\mathrm{pH}$ \\
\hline $\mathbf{C a} / \mathbf{S i}=1.0$ & & & & & & & & - \\
Alkali free & 364 & 0.17 & 1.9 & 0.0039 & - & - & 3.0 & 11.6 \\
{$[\mathrm{KOH}]=0.5 \mathrm{M}$} & 364 & 0.60 & 0.039 & 0.59 & 208 & - & 336 & 13.5 \\
{$[\mathrm{NaOH}]=0.5 \mathrm{M}$} & 364 & 0.68 & 0.059 & 0.63 & 458 & - & 360 & 13.5 \\
\hline
\end{tabular}

486

487

C-S-H

\begin{tabular}{|c|c|c|c|c|c|c|c|c|}
\hline $\begin{array}{c}\text { Inital alkali } \\
\text { concentration }\end{array}$ & $\begin{array}{l}\text { Time } \\
\text { (days) }\end{array}$ & Si & $\mathrm{Ca}$ & $\begin{array}{l}\mathrm{Al} \\
(\mathrm{mmol} / \mathrm{L})\end{array}$ & $\mathrm{K}^{*}$ & $\mathrm{Na}^{*}$ & $\mathrm{OH}$ & $\begin{array}{l}\mathrm{pH} \\
-\end{array}$ \\
\hline $\mathrm{Ca} / \mathrm{Si}=0.6$ & & & & & & & & \\
\hline $\begin{array}{r}{[\mathrm{KOH}]=0.5 \mathrm{M}} \\
\mathbf{C a} / \mathbf{S i}=\mathbf{1 . 0}\end{array}$ & 182 & 38 & $\leq 0.0025$ & - & 453 & - & 376 & 13.5 \\
\hline $\begin{array}{r}{[\mathrm{KOH}]=0.5 \mathrm{M}} \\
\mathbf{C a} / \mathbf{S i}=\mathbf{1 . 6}\end{array}$ & 182 & 0.59 & 0.08 & - & 457 & - & 419 & 13.5 \\
\hline$[\mathrm{KOH}]=0.5 \mathrm{M}$ & 182 & 0.04 & 0.80 & - & 493 & - & 420 & 13.5 \\
\hline
\end{tabular}

488

489

490 Appendix C Samples compositions (-: not observed., nm: not measured)

491

C-A-S-H (Al/Si=0.05) 


\begin{tabular}{|c|c|c|c|c|c|c|c|}
\hline \multirow{2}{*}{$\begin{array}{l}\text { Initial alkali } \\
\text { concentration }\end{array}$} & \multirow{2}{*}{$\begin{array}{l}\text { Time } \\
\text { (days) }\end{array}$} & \multicolumn{5}{|c|}{ C-S-H composition } & \multirow{2}{*}{$\begin{array}{c}\mathrm{CH} \\
\text { (wt\%) }\end{array}$} \\
\hline & & $\mathrm{Ca} / \mathrm{Si}$ & $\mathrm{Ca} /(\mathrm{Si}+\mathrm{Al})$ & $\mathrm{Al} / \mathrm{Si}$ & $\mathrm{H}_{2} \mathrm{O} / \mathrm{Si} \pm 0.3$ & $(\mathrm{KorNa}) / \mathrm{Si}$ & \\
\hline \multicolumn{8}{|l|}{$\mathrm{Ca} / \mathrm{Si}=0.6$} \\
\hline & 91 & 0.62 & 0.59 & 0.05 & 1.4 & - & - \\
\hline \multirow[t]{3}{*}{ Alkali free } & 182 & 0.62 & 0.59 & 0.05 & 1.4 & - & - \\
\hline & 364 & 0.60 & 0.57 & 0.05 & 1.1 & - & - \\
\hline & 91 & 0.61 & 0.58 & 0.05 & 1.2 & 0.031 & - \\
\hline \multirow[t]{3}{*}[\mathrm{KOH}]{$=0.01 \mathrm{M}$} & 182 & 0.61 & 0.58 & 0.05 & 1.4 & 0.032 & - \\
\hline & 364 & $\mathrm{~nm}$ & $\mathrm{~nm}$ & $\mathrm{~nm}$ & $\mathrm{~nm}$ & 0.032 & $\mathrm{~nm}$ \\
\hline & 91 & 0.64 & 0.61 & 0.05 & 1.3 & 0.13 & - \\
\hline \multirow[t]{2}{*}[\mathrm{KOH}]{$=0.05 \mathrm{M}$} & 182 & 0.63 & 0.60 & 0.05 & 1.8 & 0.15 & - \\
\hline & 364 & 0.63 & 0.60 & 0.05 & 1.2 & 0.16 & - \\
\hline \multirow[t]{3}{*}[\mathrm{KOH}]{$=0.1 \mathrm{M}$} & 91 & 0.69 & 0.66 & 0.06 & 2.2 & 0.27 & - \\
\hline & 182 & 0.67 & 0.64 & 0.06 & 1.1 & 0.25 & - \\
\hline & 364 & 0.69 & 0.65 & 0.06 & 1.2 & 0.28 & - \\
\hline \multirow[t]{2}{*}[\mathrm{KOH}]{$=0.25 \mathrm{M}$} & 91 & 0.72 & 0.68 & 0.06 & 1.3 & 0.26 & - \\
\hline & 364 & $\mathrm{~nm}$ & $\mathrm{~nm}$ & $\mathrm{~nm}$ & $\mathrm{~nm}$ & 0.33 & $\mathrm{~nm}$ \\
\hline \multirow[t]{4}{*}[\mathrm{KOH}]{$=0.5 \mathrm{M}$} & 91 & 0.72 & 0.69 & 0.05 & 1.2 & 0.24 & - \\
\hline & 182 & 0.62 & 0.59 & 0.05 & 1.1 & 0.27 & - \\
\hline & 364 & $\mathrm{~nm}$ & $\mathrm{~nm}$ & $\mathrm{~nm}$ & $\mathrm{~nm}$ & -1.21 & $\mathrm{~nm}$ \\
\hline & 91 & 0.67 & 0.63 & 0.06 & 1.4 & 0.11 & - \\
\hline \multirow[t]{2}{*}[\mathrm{NaOH}]{$=0.05 \mathrm{M}$} & 182 & 0.65 & 0.62 & 0.05 & 1.4 & 0.14 & - \\
\hline & 364 & 0.65 & 0.61 & 0.05 & 1.4 & 0.10 & - \\
\hline \multirow[t]{3}{*}[\mathrm{NaOH}]{$=0.1 \mathrm{M}$} & 91 & 0.69 & 0.65 & 0.06 & 1.4 & 0.14 & - \\
\hline & 182 & 0.70 & 0.64 & 0.06 & 1.3 & 0.26 & - \\
\hline & 364 & 0.70 & 0.66 & 0.06 & 1.4 & 0.26 & - \\
\hline \multicolumn{8}{|l|}{$\mathrm{Ca} / \mathrm{Si}=0.8$} \\
\hline & 91 & 0.81 & 0.77 & 0.05 & 1.4 & - & - \\
\hline \multirow[t]{3}{*}{ Alkali free } & 182 & 0.81 & 0.77 & 0.05 & 1.5 & - & - \\
\hline & 364 & 0.80 & 0.76 & 0.05 & 1.5 & - & - \\
\hline & 91 & 0.81 & 0.77 & 0.05 & 1.3 & 0.031 & - \\
\hline \multirow[t]{3}{*}[\mathrm{KOH}]{$=0.01 \mathrm{M}$} & 182 & 0.81 & 0.77 & 0.05 & 1.5 & 0.030 & - \\
\hline & 364 & $\mathrm{~nm}$ & $\mathrm{~nm}$ & $\mathrm{~nm}$ & $\mathrm{~nm}$ & 0.031 & $\mathrm{~nm}$ \\
\hline & 91 & 0.80 & 0.77 & 0.05 & 1.3 & 0.12 & - \\
\hline \multirow[t]{3}{*}[\mathrm{KOH}]{$=0.05 \mathrm{M}$} & 182 & 0.81 & 0.77 & 0.05 & 1.1 & 0.13 & - \\
\hline & 364 & 0.81 & 0.77 & 0.05 & 2.7 & 0.13 & - \\
\hline & 91 & 0.82 & 0.78 & 0.05 & 1.1 & 0.24 & - \\
\hline \multirow[t]{3}{*}[\mathrm{KOH}]{$=0.1 \mathrm{M}$} & 182 & 0.82 & 0.78 & 0.05 & 1.0 & 0.23 & - \\
\hline & 364 & 0.82 & 0.78 & 0.05 & 1.2 & 0.25 & - \\
\hline & 91 & 0.81 & 0.77 & 0.05 & 1.3 & 0.12 & - \\
\hline \multirow[t]{3}{*}[\mathrm{NaOH}]{$=0.05 \mathrm{M}$} & 182 & 0.82 & 0.78 & 0.05 & 1.3 & 0.15 & - \\
\hline & 364 & 0.82 & 0.78 & 0.05 & 1.4 & 0.11 & - \\
\hline & 91 & 0.83 & 0.78 & 0.05 & 1.3 & 0.12 & - \\
\hline \multirow[t]{2}{*}[\mathrm{NaOH}]{$=0.1 \mathrm{M}$} & 182 & 0.82 & 0.78 & 0.05 & 1.1 & 0.23 & - \\
\hline & 364 & 0.82 & 0.78 & 0.05 & 1.5 & 0.14 & - \\
\hline
\end{tabular}

$\mathrm{Ca} / \mathrm{Si}=1.0$ 


\begin{tabular}{|c|c|c|c|c|c|c|c|}
\hline \multirow{3}{*}{ Alkali free } & 91 & 0.99 & 0.94 & 0.05 & 1.3 & - & - \\
\hline & 182 & 0.99 & 0.94 & 0.05 & 1.4 & - & - \\
\hline & 91 & 0.99 & 0.95 & 0.05 & 1.5 & 0.013 & - \\
\hline \multirow[t]{2}{*}[\mathrm{KOH}]{$=0.01 \mathrm{M}$} & 182 & 0.99 & 0.95 & 0.05 & 1.7 & 0.013 & - \\
\hline & 364 & $\mathrm{~nm}$ & $\mathrm{~nm}$ & $\mathrm{~nm}$ & $\mathrm{~nm}$ & 0.014 & $\mathrm{~nm}$ \\
\hline \multirow{3}{*}[\mathrm{KOH}]{$=0.05 \mathrm{M}$} & 182 & 1.00 & 0.95 & 0.05 & 1.4 & 0.079 & - \\
\hline & 364 & 1.00 & 0.95 & 0.05 & 1.4 & 0.064 & - \\
\hline & 91 & 1.00 & 0.96 & 0.05 & 1.3 & 0.15 & - \\
\hline \multirow[t]{3}{*}[\mathrm{KOH}]{$=0.1 \mathrm{M}$} & 182 & 1.00 & 0.95 & 0.05 & 1.3 & 0.16 & - \\
\hline & 364 & 1.00 & 0.95 & 0.05 & 1.6 & 0.17 & - \\
\hline & 91 & 1.00 & 0.96 & 0.05 & 1.3 & 0.15 & - \\
\hline \multirow[t]{2}{*}[\mathrm{KOH}]{$=0.25 \mathrm{M}$} & 182 & 1.01 & 0.96 & 0.05 & 1.1 & 0.18 & - \\
\hline & 364 & $\mathrm{~nm}$ & $\mathrm{~nm}$ & $\mathrm{~nm}$ & $\mathrm{~nm}$ & 0.26 & $\mathrm{~nm}$ \\
\hline \multirow{3}{*}[\mathrm{KOH}]{$=0.5 \mathrm{M}$} & 91 & 1.00 & 0.96 & 0.05 & 1.2 & 0.43 & - \\
\hline & 182 & 1.01 & 0.96 & 0.05 & 1.3 & 0.19 & - \\
\hline & 91 & 1.00 & 0.95 & 0.05 & 1.4 & 0.077 & - \\
\hline \multirow{2}{*}[\mathrm{NaOH}]{$=0.05 \mathrm{M}$} & 182 & 1.00 & 0.95 & 0.05 & 1.5 & 0.10 & - \\
\hline & 364 & 1.00 & 0.95 & 0.05 & 1.5 & 0.067 & - \\
\hline \multirow[t]{2}{*}[\mathrm{NaOH}]{$=0.1 \mathrm{M}$} & 182 & 1.00 & 0.95 & 0.05 & 1.5 & 0.16 & - \\
\hline & 364 & 1.00 & 0.96 & 0.05 & 1.5 & 0.14 & - \\
\hline \multicolumn{8}{|l|}{$\mathrm{Ca} / \mathrm{Si}=1.2$} \\
\hline & 91 & 1.18 & 1.12 & 0.05 & 1.8 & - & - \\
\hline \multirow[t]{3}{*}{ Alkali free } & 182 & 1.18 & 1.12 & 0.05 & 1.9 & - & - \\
\hline & 364 & $\mathrm{~nm}$ & $\mathrm{~nm}$ & $\mathrm{~nm}$ & $\mathrm{~nm}$ & - & $\mathrm{nm}$ \\
\hline & 91 & 1.18 & 1.12 & 0.05 & 1.6 & 0.0037 & - \\
\hline \multirow[t]{2}{*}[\mathrm{KOH}]{$=0.01 \mathrm{M}$} & 182 & 1.18 & 1.12 & 0.05 & 1.8 & 0.0043 & - \\
\hline & 364 & $\mathrm{~nm}$ & $\mathrm{~nm}$ & $\mathrm{~nm}$ & $\mathrm{~nm}$ & 0.0052 & $\mathrm{~nm}$ \\
\hline \multirow{3}{*}[\mathrm{KOH}]{$=0.05 \mathrm{M}$} & 182 & 1.19 & 1.14 & 0.05 & 1.5 & 0.030 & - \\
\hline & 364 & 1.19 & 1.14 & 0.05 & 1.3 & 0.018 & - \\
\hline & 91 & 1.20 & 1.14 & 0.05 & 1.2 & 0.092 & - \\
\hline \multirow[t]{3}{*}[\mathrm{KOH}]{$=0.1 \mathrm{M}$} & 182 & 1.20 & 1.14 & 0.05 & 1.3 & 0.095 & - \\
\hline & 364 & 1.20 & 1.14 & 0.05 & 1.7 & 0.10 & - \\
\hline & 91 & 1.20 & 1.14 & 0.05 & 1.3 & 0.068 & - \\
\hline \multirow[t]{3}{*}[\mathrm{KOH}]{$=0.25 \mathrm{M}$} & 182 & 1.19 & 1.13 & 0.05 & 1.4 & -0.04 & - \\
\hline & 364 & $\mathrm{~nm}$ & $\mathrm{~nm}$ & $\mathrm{~nm}$ & $\mathrm{~nm}$ & 0.32 & $\mathrm{~nm}$ \\
\hline & 91 & 1.20 & 1.14 & 0.05 & 1.6 & 0.043 & - \\
\hline \multirow[t]{2}{*}[\mathrm{NaOH}]{$=0.05 \mathrm{M}$} & 182 & 1.20 & 1.14 & 0.05 & 1.6 & 0.041 & - \\
\hline & 364 & 1.20 & 1.14 & 0.05 & 1.6 & 0.029 & - \\
\hline \multirow{2}{*}[\mathrm{NaOH}]{$=0.1 \mathrm{M}$} & 182 & 1.20 & 1.14 & 0.05 & 1.5 & 0.11 & - \\
\hline & 364 & 1.20 & 1.14 & 0.05 & 1.7 & 0.079 & - \\
\hline \multicolumn{8}{|l|}{$\mathrm{Ca} / \mathrm{Si}=1.4$} \\
\hline & 91 & 1.32 & 1.25 & 0.05 & 1.6 & - & - \\
\hline \multirow[t]{3}{*}{ Alkali free } & 182 & 1.32 & 1.26 & 0.05 & 1.9 & - & - \\
\hline & 364 & $\mathrm{~nm}$ & $\mathrm{~nm}$ & $\mathrm{~nm}$ & $\mathrm{~nm}$ & - & $\mathrm{nm}$ \\
\hline & 91 & $\mathrm{~nm}$ & $\mathrm{~nm}$ & $\mathrm{~nm}$ & $\mathrm{~nm}$ & 0.0010 & $\mathrm{~nm}$ \\
\hline \multirow[t]{3}{*}[\mathrm{KOH}]{$=0.01 \mathrm{M}$} & 182 & $\mathrm{~nm}$ & $\mathrm{~nm}$ & $\mathrm{~nm}$ & $\mathrm{~nm}$ & 0.0014 & $\mathrm{~nm}$ \\
\hline & 364 & $\mathrm{~nm}$ & $\mathrm{~nm}$ & $\mathrm{~nm}$ & $\mathrm{~nm}$ & 0.0021 & $\mathrm{~nm}$ \\
\hline & \multicolumn{7}{|c|}{$33 / 39$} \\
\hline
\end{tabular}




\begin{tabular}{|c|c|c|c|c|c|c|c|}
\hline & 91 & 1.36 & 1.29 & 0.05 & 1.9 & -0.0060 & - \\
\hline \multirow[t]{2}{*}[\mathrm{KOH}]{$=0.05 \mathrm{M}$} & 182 & 1.36 & 1.29 & 0.05 & 1.7 & -0.0076 & - \\
\hline & 364 & 1.36 & 1.29 & 0.05 & 1.6 & -0.0079 & - \\
\hline \multirow[t]{2}{*}[\mathrm{KOH}]{$=0.1 \mathrm{M}$} & 182 & 1.39 & 1.33 & 0.05 & 1.5 & 0.031 & - \\
\hline & 364 & $\mathrm{~nm}$ & $\mathrm{~nm}$ & $\mathrm{~nm}$ & $\mathrm{~nm}$ & 0.034 & $\mathrm{~nm}$ \\
\hline \multirow[t]{3}{*}[\mathrm{NaOH}]{$=0.05 \mathrm{M}$} & 91 & 1.38 & 1.31 & 0.05 & 2.0 & 0.00063 & - \\
\hline & 182 & 1.38 & 1.31 & 0.05 & 1.6 & 0.011 & - \\
\hline & 364 & 1.38 & 1.31 & 0.05 & 1.7 & -0.0088 & - \\
\hline \multirow[t]{3}{*}[\mathrm{NaOH}]{$=0.1 \mathrm{M}$} & 91 & 1.39 & 1.32 & 0.05 & 1.9 & -0.14 & - \\
\hline & 182 & 1.30 & 1.23 & 0.05 & 1.6 & 0.038 & 4.08 \\
\hline & 364 & 1.39 & 1.32 & 0.05 & 1.8 & 0.0048 & - \\
\hline \multicolumn{8}{|l|}{$\mathrm{Ca} / \mathrm{Si}=1.6$} \\
\hline \multirow{3}{*}{ Alkali free } & 91 & 1.43 & 1.37 & 0.05 & 1.8 & - & 0.71 \\
\hline & 182 & 1.44 & 1.37 & 0.05 & 1.9 & - & 1.68 \\
\hline & 364 & 1.39 & 1.33 & 0.05 & 1.9 & - & 2.32 \\
\hline \multirow{3}{*}[\mathrm{KOH}]{$=0.01 \mathrm{M}$} & 91 & 1.409 & 1.342 & 0.05 & 1.5 & -0.0010 & 3.21 \\
\hline & 182 & 1.437 & 1.368 & 0.05 & 1.8 & 0.000093 & 2.69 \\
\hline & 364 & $\mathrm{~nm}$ & $\mathrm{~nm}$ & $\mathrm{~nm}$ & $\mathrm{~nm}$ & 0.0022 & $\mathrm{~nm}$ \\
\hline \multirow{3}{*}[\mathrm{KOH}]{$=0.05 \mathrm{M}$} & 91 & 1.46 & 1.39 & 0.05 & 1.9 & -0.014 & 3.17 \\
\hline & 182 & 1.45 & 1.38 & 0.05 & 1.7 & 0.0031 & 3.79 \\
\hline & 364 & 1.40 & 1.34 & 0.05 & 1.7 & -0.008 & 5.3 \\
\hline \multirow{3}{*}[\mathrm{KOH}]{$=0.1 \mathrm{M}$} & 91 & 1.54 & 1.47 & 0.05 & 1.9 & 0.012 & 1.2 \\
\hline & 182 & 1.52 & 1.44 & 0.05 & 1.7 & 0.016 & 2.2 \\
\hline & 364 & $\mathrm{~nm}$ & $\mathrm{~nm}$ & $\mathrm{~nm}$ & $\mathrm{~nm}$ & 0.0081 & $\mathrm{~nm}$ \\
\hline \multirow{3}{*}[\mathrm{KOH}]{$=0.25 \mathrm{M}$} & 91 & 1.43 & 1.36 & 0.05 & 1.4 & -0.11 & 6.42 \\
\hline & 182 & $\mathrm{~nm}$ & $\mathrm{~nm}$ & $\mathrm{~nm}$ & $\mathrm{~nm}$ & 0.063 & $\mathrm{~nm}$ \\
\hline & 364 & 1.46 & 1.39 & 0.05 & 2.1 & $\mathrm{~nm}$ & 5.11 \\
\hline \multirow{3}{*}[\mathrm{KOH}]{$=0.5 \mathrm{M}$} & 91 & 1.44 & 1.37 & 0.05 & 1.5 & -0.038 & 6.42 \\
\hline & 182 & 1.25 & 1.19 & 0.05 & 1.3 & -0.34 & 14 \\
\hline & 364 & 1.20 & 1.14 & 0.05 & 1.4 & -0.37 & 16 \\
\hline \multirow{4}{*}[\mathrm{NaOH}]{$=0.05 \mathrm{M}$} & 91 & 1.51 & 1.44 & 0.05 & 2.0 & -0.014 & 1.19 \\
\hline & 182 & 1.51 & 1.44 & 0.05 & 1.7 & 0.0055 & 1.87 \\
\hline & 364 & $\mathrm{~nm}$ & $\mathrm{~nm}$ & $\mathrm{~nm}$ & $\mathrm{~nm}$ & -0.015 & $\mathrm{~nm}$ \\
\hline & 364 & $\mathrm{~nm}$ & $\mathrm{~nm}$ & $\mathrm{~nm}$ & $\mathrm{~nm}$ & -0.018 & $\mathrm{~nm}$ \\
\hline \multirow{3}{*}[\mathrm{NaOH}]{$=0.1 \mathrm{M}$} & 91 & 1.54 & 1.47 & 0.05 & 1.9 & -0.17 & 1.22 \\
\hline & 182 & 1.51 & 1.44 & 0.05 & 1.9 & 0.019 & 2.46 \\
\hline & 364 & $\mathrm{~nm}$ & $\mathrm{~nm}$ & $\mathrm{~nm}$ & $\mathrm{~nm}$ & -0.018 & $\mathrm{~nm}$ \\
\hline
\end{tabular}

C-S-H

\begin{tabular}{|c|c|c|c|c|c|c|c|}
\hline \multirow{2}{*}{$\begin{array}{l}\text { Initial alkali } \\
\text { concentration }\end{array}$} & \multirow{2}{*}{$\begin{array}{l}\text { Time } \\
\text { (days) }\end{array}$} & \multicolumn{5}{|c|}{ C-S-H composition } & \multirow{2}{*}{$\begin{array}{c}\mathrm{CH} \\
(\mathrm{wt} \%)\end{array}$} \\
\hline & & $\mathrm{Ca} / \mathrm{Si}^{1}$ & $\mathrm{Ca} /(\mathrm{Si}+\mathrm{Al})^{1}$ & $\mathrm{Al} / \mathrm{Si}^{1}$ & $\mathrm{H}_{2} \mathrm{O} / \mathrm{Si} \pm 0.3$ & (KorNa)/Si & \\
\hline $\mathrm{Ca} / \mathrm{Si}=0.6$ & & & & & & & \\
\hline $\begin{array}{r}{[\mathrm{KOH}]=0.5 \mathrm{M}} \\
\mathrm{Ca} / \mathrm{Si}=\mathbf{1 . 0}\end{array}$ & 182 & 0.72 & 0.72 & - & 1.3 & 0.23 & - \\
\hline $\begin{array}{r}{[\mathrm{KOH}]=0.5 \mathrm{M}} \\
\mathrm{Ca} / \mathrm{Si}=1.6\end{array}$ & 182 & 1.0 & 1.0 & - & 1.3 & 0.21 & - \\
\hline
\end{tabular}




\section{Reference}

[1] T.T.H. Bach, E. Chabas, I. Pochard, C. Cau Dit Coumes, J. Haas, F. Frizon, A. Nonat, Retention of alkali ions by hydrated low-pH cements: Mechanism and Na+/K+ selectivity, Cem Concr Res, 51 (2013) 1421.

[2] D.E. Macphee, K. Luke, F.P. Glasser, E.E. Lachowski, Solubility and aging of calcium silicate hydrates in alkaline solutions at $25^{\circ} \mathrm{C}$, J Am Ceram Soc, 72 (1989) 646-654.

[3] S.-Y. Hong, F.P. Glasser, Alkali binding in cement pastes. Part I. The C-S-H phase, Cem Concr Res, 29 (1999) 1893-1903.

[4] E. L'Hôpital, B. Lothenbach, G. Le Saout, D. Kulik, K. Scrivener, Incorporation of aluminium in calcium-silicate-hydrates, Cem Concr Res, 75 (2015) 91-103.

[5] R.N. Swamy, The Alkali-Silica Reaction in Concrete, CRC Press2002.

[6] A. Leemann, B. Lothenbach, C. Thalmann, Influence of superplasticizers on pore solution composition and on expansion of concrete due to alkali-silica reaction, Constr Build Mat, 25 (2011) 344-350.

[7] M. Ochs, I. Pointeau, E. Giffaut, Caesium sorption by hydrated cement as a function of degradation state: Experiments and modelling, Waste Management, 26 (2006) 725-732.

[8] T. Chappex, K. Scrivener, Alkali fixation of C-S-H in blended cement pastes and its relation to alkali silica reaction, Cem Concr Res, 42 (2012) 1049-1054.

[9] I. Richardson, The nature of CSH in hardened cements, Cem Concr Res, 29 (1999) 1131-1147.

[10] R.J. Myers, S.A. Bernal, R. San Nicolas, J.L. Provis, Generalized structural description of calciumsodium aluminosilicate hydrate gels: the cross-linked substituted tobermorite model, Langmuir, 29 (2013) 5294-5306.

[11] H. Stade, On the reaction of C-S-H(di,poly) with alkali hydroxides, Cem Concr Res, 19 (1989) 802810.

[12] B. Lothenbach, G. Le Saout, M. Ben Haha, R. Figi, E. Wieland, Hydration of a low-alkali CEM III/B$\mathrm{SiO}_{2}$ cement (LAC), Cem Concr Res, 42 (2012) 410-423.

[13] B. Lothenbach, D. Rentsch, E. Wieland, Hydration of a silica fume blended shotcrete cement, J Phys Chem Earth, 70-71 (2014) 3-16.

[14] G.L. Kalousek, Studies of portions of the quarternary system soda-lime-silica-water at $25^{\circ} \mathrm{C}$, J Res Nat Bur Stand, 32 (1944) 285-302.

[15] J. Tits, E. Wieland, C.J. Müller, C. Landesman, M.H. Bradbury, Strontium binding by calcium silicate hydrates, J Colloid Interface Sci, 300 (2006) 78-87.

[16] B. Lothenbach, E. Wieland, A thermodynamic approach to the hydration of sulphate-resisting Portland cement, Waste Management, 26 (2006) 706-719.

[17] B. Lothenbach, F. Winnefeld, Thermodynamic modelling of the hydration of Portland cement, Cem Concr Res, 36 (2006) 209-226.

[18] B. Lothenbach, F. Winnefeld, C. Alder, E. Wieland, P. Lunk, Effect of temperature on the pore solution, microstructure and hydration products of Portland cement pastes, Cem Concr Res, 37 (2007) 483-491.

[19] H.F.W. Taylor, A method for predicting alkali ion concentrations in cement pore solutions, Adv Cem Res, 1 (1987) 5-17.

[20] S.-Y. Hong, F.P. Glasser, Alkali sorption by C-S-H and C-A-S-H gels. Part II. Role of alumina, Cem Concr Res, 32 (2002) 1101-1111.

[21] I. Lognot, I. Klur, A. Nonat, NMR and infrared spectroscopies of C-S-H and Al-substituted C-S-H synthesised in alkaline solutions, in: P. Colombet, H. Zanni, A.-R. Grimmer, P. Sozzani (Eds.) Nuclear 
Magnetic Resonance Spectroscopy of Cement-Based Materials, Springer Berlin Heidelberg1998, pp. 541 189-196.

542 [22] H. Viallis, P. Faucon, J.-C. Petit, A. Nonat, Interaction between salts $(\mathrm{NaCl}, \mathrm{CsCl})$ and calcium silicate hydrates (CSH), J Phys Chem B, 103 (1999) 5212-5219.

544 [23] G. Renaudin, J. Russias, F. Leroux, C. Cau-dit-Coumes, F. Frizon, Structural characterization of C-S-H 545 and C-A-S-H samples-Part II: Local environment investigated by spectroscopic analyses, J Solid State 546 Chem, 182 (2009) 3320-3329.

547 [24] E. L'Hôpital, B. Lothenbach, D. Kulik, K. Scrivener, Influence of the Ca/Si on the aluminium uptake 548 in C-S-H, Cem Concr Res, submitted.

549 [25] D. Massiot, F. Fayon, M. Capron, I. King, S. Le Calvé, B. Alonso, J.O. Durand, B. Bujoli, Z. Gan, G. 550 Hoatson, Modelling one- and two-dimensional solid-state NMR spectra, Magnetic Resonance Chem, 55140 (2002) 70-76.

552 [26] D.A. Kulik, T. Wagner, S.V. Dmytrieva, G. Kosakowski, F.F. Hingerl, K.V. Chudnenko, U.R. Berner, 553 GEM-Selektor geochemical modeling package: revised algorithm and GEMS3K numerical kernel for 554 coupled simulation codes, Computational Geosciences, 17 (2013) 1-24.

555 [27] T. Wagner, D.A. Kulik, F.F. Hingerl, S.V. Dmytrieva, GEM-Selektor geochemical modeling package: 556 TSolMod library and data interface for multicomponent phase models, Canadian Mineralogist, 50 557 (2012) 1173-1195.

558 [28] D. Langmuir, P. Hall, J. Drever, Environmental Geochemistry, Prentice Hall, New Jersey1997.

559 [29] T. Thoenen, D. Kulik, Nagra/PSI chemical thermodynamic database 01/01 for the GEM-Selektor 560 (V.2-PSI) geochemical modeling code, PSI, Villigen; available at http://gems.web.psi.ch/doc/pdf/TM561 44-03-04-web.pdf, 2003.

562 [30] W. Hummel, U. Berner, E. Curti, F.J. Pearson, T. Thoenen, Nagra/PSI Chemical Thermodynamic Data Base 01/01, Universal Publishers/uPUBLISH.com, USA, also published as Nagra Technical Report NTB 02-16, Wettingen, Switzerland, 2002.

[31] B. Lothenbach, T. Matschei, G. Moschner, F.P. Glasser, Thermodynamic modelling of the effect of temperature on the hydration and porosity of Portland cement, Cem Concr Res, 38 (2008) 1-18.

[32] T. Matschei, B. Lothenbach, F.P. Glasser, Thermodynamic properties of Portland cement hydrates in the system $\mathrm{CaO}-\mathrm{Al}_{2} \mathrm{O}_{3}-\mathrm{SiO}_{2}-\mathrm{CaSO}_{4}-\mathrm{CaCO}_{3}-\mathrm{H}_{2} \mathrm{O}$, Cem Concr Res, 37 (2007) 1379-1410.

[33] B. Lothenbach, L. Pelletier-Chaignat, F. Winnefeld, Stability in the system $\mathrm{CaO}-\mathrm{Al}_{2} \mathrm{O}_{3}-\mathrm{H}_{2} \mathrm{O}, \mathrm{Cem}$ 570 Concr Res, 42 (2012) 1621-1634.

[34] B.Z. Dilnesa, B. Lothenbach, G. Renaudin, A. Wichser, D. Kulik, Synthesis and characterization of hydrogarnet $\mathrm{Ca}_{3}\left(\mathrm{Al}_{x} \mathrm{Fe}_{1-\mathrm{x}}\right)_{2}\left(\mathrm{SiO}_{4}\right)_{y}(\mathrm{OH})_{4(3-\mathrm{y})}$, Cem Concr Res, 59 (2014) 96-111.

[35] D.A. Kulik, Improving the structural consistency of C-S-H solid solution thermodynamic models, Cem Concr Res, 41 (2011) 477-495.

[36] H.C. Helgeson, D.H. Kirkham, G.C. Flowers, Theoretical prediction of the thermodynamic behaviour of aqueous electrolyte at high pressures and temperatures. IV. Calculation of activity coefficients, osmotic coefficients, and apparent molal and standard and relative molal properties to $600{ }^{\circ} \mathrm{C}$ and 5 kb, Am J Sci, 281 (1981) 1249-1516.

579 [37] B.J. Merkel, B. Planer-Friederich, Groundwater Geochemistry. A Practical Guide to Modeling of 580 Natural and Contaminated Aquatic Systems, Springer Berlin2008.

[38] R.J. Myers, E. L'Hôpital, J.L. Provis, B. Lothenbach, Composition-solubility-structure relationships in calcium (alkali) aluminosilicate hydrate (C-(N,K-)A-S-H), Dalton Transactions, 44 (2015) 13530-13544.

586 [40] E. Bonaccorsi, S. Merlino, The crystal structure of tobermorite 14 A (plombierite), a C-S-H phase, J

[39] G. Renaudin, J. Russias, F. Leroux, F. Frizon, C. Cau-Dit-Coumes, Structural characterization of C-S$\mathrm{H}$ and C-A-S-H samples-Part I: Long-range order investigated by Rietveld analyses, J Solid State Chem, 182 (2009) 3312-3319.

Am Ceram Soc, 88 (2005) 505-512. 
[41] I. Lognot, Etude de l'hydratation du laitier de hauts fourneaux et de ses produits en présence de différents activants. Application aux coulis d'injection., Thesis, (1996).

[42] J.J. Chen, J.J. Thomas, H.F.W. Taylor, H.M. Jennings, Solubility and structure of calcium silicate hydrate, Cem Concr Res, 34 (2004) 1499-1519.

[43] A.V. Girao, I.G. Richardson, R. Taylor, R.M.D. Brydson, Composition, morphology and nanostructure of C-S-H in $70 \%$ white Portland cement - 30\% fly ash blends hydrated at $55^{\circ} \mathrm{C}$, Cem Concr Res, 40 (2010) 1350-1359.

[44] H. Sato, M. Grutzeck, Effect of starting materials on the synthesis of tobermorite, MRS Proceedings, Cambridge Univ Press, 1991, pp. 235.

[45] G. Le Saout, E. Lécolier, A. Rivereau, H. Zanni, Chemical structure of cement aged at normal and elevated temperatures and pressures. Part I. Class G oilwell cement, Cem Concr Res, 36 (2006) 71-78.

[46] G. Le Saout, E. Lécolier, A. Rivereau, H. Zanni, Chemical structure of cement aged at normal and elevated temperatures and pressures. Part II. Low permeability class G oilwell cement, Cem Concr Res, 36 (2006) 428-433.

[47] G.K. Sun, J.F. Young, R.J. Kirkpatrick, The role of Al in C-S-H: NMR, XRD, and compositional results for precipitated samples, Cem Concr Res, 36 (2006) 18-29.

[48] J. Skibsted, M.D. Andersen, The effect of alkali ions on the incorporation of aluminum in the calcium silicate hydrate (C-S-H) phase resulting from Portland cement hydration studied by 29Si MAS NMR, J Am Ceram Soc, 96 (2013) 651-656.

[49] M.D. Andersen, H.J. Jakobsen, J. Skibsted, Incorporation of aluminum in the calcium silicate hydrate (C-S-H) of hydrated Portland cements: A high-field Al-27 and Si-29 MAS NMR Investigation, Inorg Chem, 42 (2003) 2280-2287.

[50] X. Pardal, F. Brunet, T. Charpentier, I. Pochard, A. Nonat, Al-27 and Si-29 solid-state NMR characterization of calcium-cluminosilicate-hydrate, Inorg Chem, 51 (2012) 1827-1836.

[51] I.G. Richardson, A.R. Brough, R. Brydson, G.W. Groves, C.M. Dobson, Location of Aluminum in Substituted Calcium Silicate Hydrate (C-S-H) Gels as Determined by Si-29 and Al-27 Nmr and Eels, J Am Ceram Soc, 76 (1993) 2285-2288.

[52] B. Lothenbach, A. Nonat, Calcium silicate hydrates: solid and liquid phase composition, Cem Concr Res, 78 (2015) 57-70.

[53] W. Kunther, B. Lothenbach, J. Skibsted, Influence of the Ca/Si ratio of the C-S-H phase on the interaction with sulfate ions and its impact on the ettringite crystallization pressure, Cem Concr Res, 69 (2015) 37-49.

[54] M. Magi, E. Lippmaa, A. Samoson, G. Engelhardt, A. Grimmer, Solid-state high-resolution silicon-29 chemical shifts in silicates, J Phys Chem, 88 (1984) 1518-1522.

[55] P. Rejmak, J.S. Dolado, M.J. Stott, A.s. Ayuela, 29Si NMR in cement: a theoretical study on calcium silicate hydrates, J Phys Chem C, 116 (2012) 9755-9761.

[56] I. Klur, B. Pollet, J. Virlet, A. Nonat, C-S-H structure evolution with calcium content by multinuclear NMR, in: P. Colombet, A.-R. Grimmer, H. Zanni, P. Soozzani (Eds.) Nuclear Magnetic Resonance Spectroscopy of Cement-Based Materials, Springer, Berlin, 1998, pp. 119-141.

[57] C. Labbez, I. Pochard, B. Jönsson, A. Nonat, C-S-H/solution interface: Experimental and Monte Carlo studies, Cem Concr Res, 41 (2011) 161-168.

[58] C. Labbez, B. Jönsson, I. Pochard, A. Nonat, B. Cabane, Surface charge density and electrokinetic potential of highly charged minerals: experiments and Monte Carlo simulations on calcium silicate hydrate, J Phys Chem B, 110 (2006) 9219-9230.

[59] J. Haas, A. Nonat, From C-S-H to C-A-S-H: Experimental study and thermodynamic modelling, Cem Concr Res, 68 (2015) 124-138.

[60] R. Myers, S.A. Bernal, J.L. Provis, A thermodynamic model for C-(N-)A-S-H gel: CNASH_ss.

Derivation and validation, Cem Concr Res, 66 (2014) 27-47. 
[61] D.A. Kulik, G.D. Miron, B. Lothenbach, Aqueous solubility of C-S-H gel-like phases containing Al, K and $\mathrm{Na}$, revisited with a structurally-consistent CASHNK multi-site non-ideal solid solution model, in 638 preparation.

639 [62] D.A. Kulik, Improving the structural consistency of C-S-H solid solution thermodynamic models, 640 Cem Concr Res, 41 (2011) 477-495.

641 [63] H. Viallis-Terrisse, A. Nonat, J.C. Petit, C. Landesman, C. Richet, Specific interaction of cesium with 642 the surface of calcium silicate hydrates, Radiochim Acta, 90 (2002) 699-704.

643 [64] F. Winnefeld, B. Lothenbach, Hydration of calcium sulfoaluminate cements: experimental findings 644 and thermodynamic modelling, Cem Concr Res, 40 (2010) 1239-1247.

645 [65] S.V. Churakov, C. Labbez, L. Pegado, M. Sulpizi, Intrinsic Acidity of Surface Sites in Calcium Silicate 646 Hydrates and Its Implication to Their Electrokinetic Properties, J Phys Chem C, 118 (2014) 11752-11762.

647 [66] J. Haas, A. Nonat, From C-S-H to C-A-S-H: Experimental study and thermodynamic modelling, 648 Cement Concrete Res, 68 (2015) 124-138.

649 [67] A. Leemann, L. Loertscher, L. Bernard, G. Le Saout, B. Lothenbach, R. Espinosa-Marzal, Mitigation of 650 ASR by the use of $\mathrm{LiNO}_{3}$ - characterization of the reaction products, Cem Concr Res, 59 (2014) 73-86.

651 [68] L. Pegado, C. Labbez, S.V. Churakov, Mechanism of aluminium incorporation into C-S-H from ab 652 initio calculations, J Mat Chem A, 2 (2014) 3477-3483.

653 [69] Y. Kim, R. James Kirkpatrick, ${ }^{23} \mathrm{Na}$ and ${ }^{133} \mathrm{Cs}$ NMR study of cation adsorption on mineral surfaces:

654 Local environments, dynamics, and effects of mixed cations, Geochim Cosmochim Acta, 61 (1997)

655 5199-5208.

656 [70] H. Viallis-Terrisse, A. Nonat, J.C. Petit, Zeta-potential study of calcium silicate hydrates interacting 657 with alkaline cations, J Colloid Interface Sci, 253 (2001) 140-149. 